\title{
CLIMATOLOGICAL DATA FOR CLOUDS OVER THE GLOBE FROM SURFACE OBSERVATIONS, 1982-1991: THE TOTAL CLOUD EDITION
}

Carole J. Hahn

Cooperative Institute for Research in Environmental Sciences

University of Colorado

Boulder, Colorado 80309

Stephen G. Warren

Department of Atmospheric Sciences

University of Washington

Seattle, Washington 98195

Julius London

Department of Astrophysical, Planetary and Atmospheric Sciences

University of Colorado

Boulder, Colorado 80309

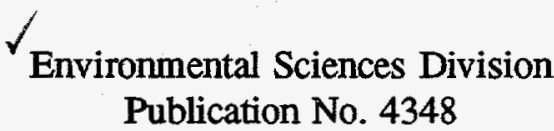

Date Published: October 1994

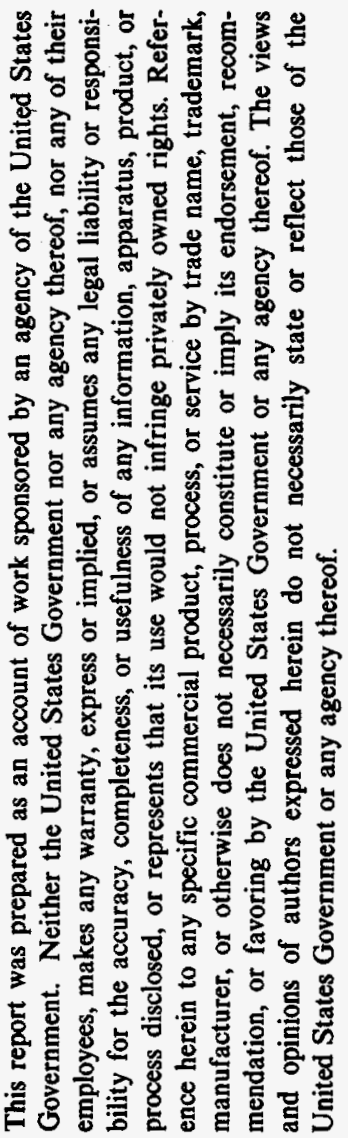

Printed for the

Global Change Research Program

Environmental Sciences Division

Office of Health and Environmental Research

U.S. Department of Energy

(KP 0500000 )

Printed by the

Carbon Dioxide Information Analysis Center

OAK RIDGE NATIONAL LABORATORY

Oak Ridge, Tennessee 37831-6335

managed by

MARTIN MARIETTA ENERGY SYSTEMS, INC.

for the

U.S. DEPARTMENT OF ENERGY

under contract DE-AC05-84OR21400 



\section{DISCLAIMER}

Portions of this document may be illegible in electronic image products. Images are produced from the best available original document. 


\section{TABLE OF CONTENTS}

Page

LIST OF TABLES $\ldots \ldots \ldots \ldots \ldots \ldots \ldots \ldots \ldots \ldots \ldots \ldots \ldots \ldots \ldots$

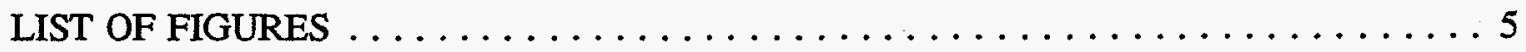

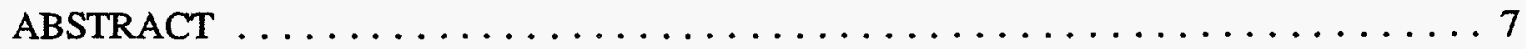

1. INTRODUCTION $\ldots \ldots \ldots \ldots \ldots \ldots \ldots \ldots \ldots \ldots \ldots \ldots \ldots$

2. DATA SOURCE AND ANALYSIS $\ldots \ldots \ldots \ldots \ldots \ldots \ldots \ldots$

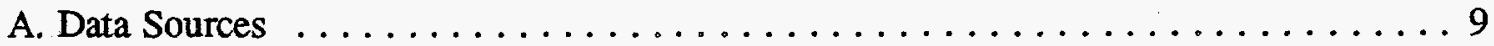

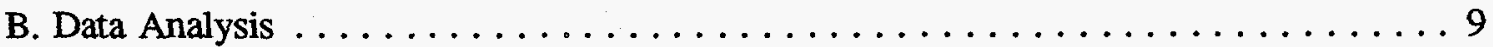

1) Processing of Weather Reports . . . . . . . . . . . . . . 9

2) Determination of Cloudiness at Night $\ldots \ldots \ldots \ldots \ldots \ldots \ldots \ldots \ldots \ldots$

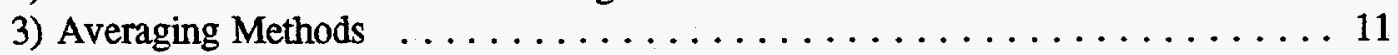

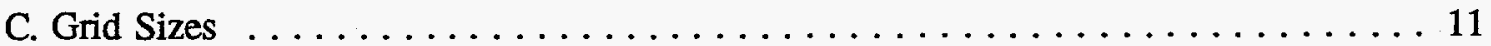

3. CONTENTS AND ORGANIZATION OF THE DATA ARCHIVE $\ldots \ldots \ldots \ldots \ldots$

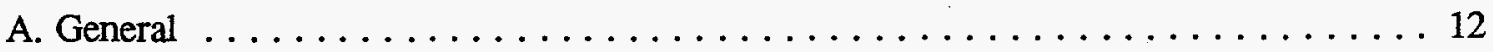

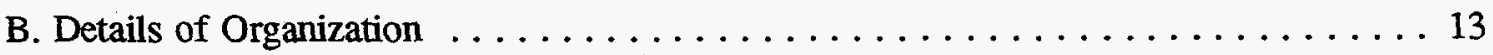

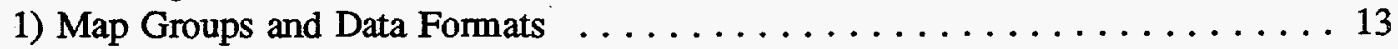

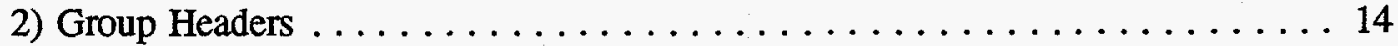

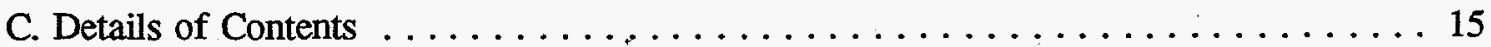

1) The Missing Value Code . . . . . . . . . . . . . . . . . 15

2) File 2: Grid Information; format $10 \ldots \ldots \ldots \ldots \ldots \ldots \ldots \ldots \ldots \ldots$

3) File 3: Land and Ocean Combined; formats $22,32 \ldots \ldots \ldots \ldots \ldots \ldots$

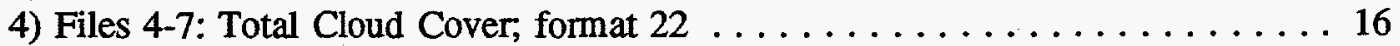

5) Files 8-15: Weather Types; format $32 \ldots \ldots \ldots \ldots \ldots \ldots \ldots \ldots$

6) File 16: Harmonics, Interannual Variations and Trends; formats $40-42,51-52 \ldots \ldots \ldots \ldots \ldots \ldots \ldots \ldots$

4. HOW TO OBTAIN THE DATA ... . . . . . . . . . . . . 19

ACKNOWLEDGEMENTS $\ldots \ldots \ldots \ldots \ldots \ldots \ldots \ldots \ldots \ldots \ldots \ldots \ldots$

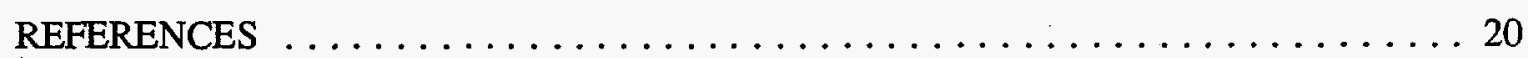

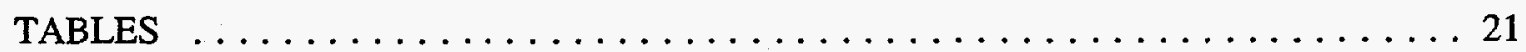

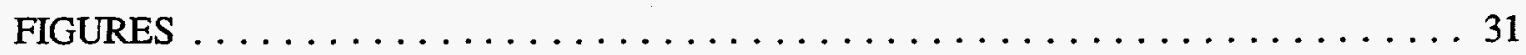




\section{LIST OF TABLES}

Table

Page

1. Cloud Information Contained in Synoptic Weather Reports . . . . . . . . . . . 21

2. Cloud and Weather Type Definitions Used in Total Cloud Edition $\ldots \ldots \ldots \ldots \ldots \ldots$

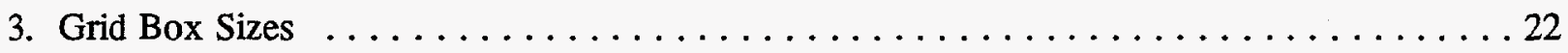

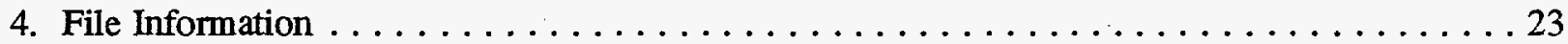

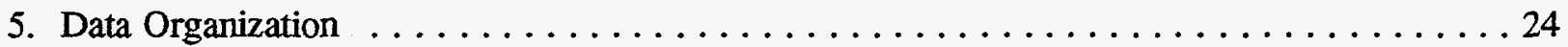

6. List of Formats for Reading Data Records $\ldots \ldots \ldots \ldots \ldots \ldots \ldots \ldots \ldots \ldots \ldots \ldots \ldots \ldots$

7. Map Group Header Record Format and Codes $\ldots \ldots \ldots \ldots \ldots \ldots \ldots \ldots \ldots \ldots$

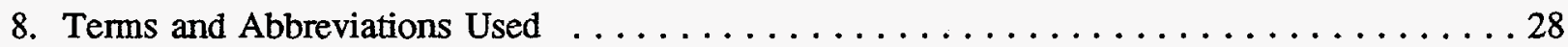




\section{LIST OF FIGURES}

$\underline{\text { Figure }}$

$\underline{\text { Page }}$

1. Flow chart of data selection and checking $\ldots \ldots \ldots \ldots \ldots \ldots \ldots \ldots \ldots \ldots \ldots$

2a. Annual Average Total Cloud Cover (\%), Land \& Ocean, 1982-1991 . . . . . . . . 32

2b. Annual Precipitation Frequency (\%), Land \& Ocean, $1982-1991 \ldots \ldots \ldots \ldots \ldots$

3a. Phase of Annual Cycle in Total Cloud Cover for Ocean . . . . . . . . . . . . . 34

3b. Phase of Annual Cycle in Precipitation Frequency for Ocean $\ldots \ldots \ldots \ldots \ldots \ldots \ldots$

3c. Phase of Annual Cycle in Fog Frequency for Ocean $\ldots \ldots \ldots \ldots \ldots \ldots \ldots$

4a. Diumal Cycle in Total Cloud Cover for DJF (1982-1991) Ocean . . . . . . . . . . 37

4b. Diurnal Cycle in Total Cloud Cover for MAM (1982-1991) Ocean . . . . . . . . . . 38

4c. Diumal Cycle in Total Cloud Cover for JJA (1982-1991) Ocean . . . . . . . . . . . . 39

4d. Diumal Cycle in Total Cloud Cover for SON (1982-1991) Ocean . . . . . . . . . . 40

5a. Diumal Cycle in Total Cloud Cover for DJF (1982-1991) Land, over China . . . . . . . . 41

5b. Diurnal Cycle in Total Cloud Cover for JJA (1982-1991) Land, over the U. S. . . . . . . 42 


\begin{abstract}
Hahn, C.J., S.G. Warren, and J. London, 1994: Climatological Data for Clouds Over the Globe from Surface Observations, 1982-1991: The Total Cloud Edition. NDP026A, Carbon Dioxide Information Analysis Center, Oak Ridge National Laboratory, Oak Ridge, TN. (Also available from Data Support Section, National Center for Atmospheric Research, Boulder, CO.)

Routine, surface synoptic weather reports from ships and land stations over the entire globe, for the ten-year period December 1981 through November 1991, were processed for total cloud cover and the frequencies of occurrence of clear sky, precipitation, and sky-obscured due to fog. Archived data, consisting of various annual, seasonal and monthly averages, are provided in grid boxes that are typically $2.5^{\circ} \times 2.5^{\circ}$ for land and $5^{\circ} \times 5^{\circ}$ for ocean. Day and nighttime averages are also given separately for each season. Several derived quantities, such as interannual variations and annual and diumal harmonics, are provided as well. This data set incorporates an improved representation of nighttime cloudiness by utilizing only those nighttime observations for which the illuminance due to moonlight exceeds a specified threshold. This reduction in the night-detection bias increases the computed global average total cloud cover by about $2 \%$. The impact on computed diurnal cycles is even greater, particularly over the oceans where is found, in contrast to previous surface-based climatologies, that cloudiness is often greater at night than during the day.
\end{abstract}




\section{INTRODUCTION}

This report describes a data archive that contains global coverage of analyzed cloud data. The cloud data contained in this archive (the "Total Cloud Edition") are for total cloud cover. In addition, the frequencies of occurrence of clear sky, precipitation, and sky-obscured due to fog (collectively referred to here as "weather types") are also included. Analyses of cloud types are not provided here. All data utilized here were obtained from routine, surface synoptic weather reports for the ten-year period December 1981 through November 1991. The specific contents of the archive are described in Section 3. Briefly, the archive contains various annual, seasonal and monthly averages for total cloud and the three weather types in grid boxes that are typically $2.5^{\circ} \times 2.5^{\circ}$ for land and $5^{\circ} \times 5^{\circ}$ for ocean. Several derived quantities, such as interannual variations and annual and diumal harmonics, are also provided.

Previously the authors prepared a similar cloud data archive that spanned the years 1930 to 1981 (Hahn et al., 1988). Some of the data contained in that archive were presented in published atlases (Warren et al., 1986, 1988). The present archive represents not only an extension of the time period analyzed, but an improvement in the analysis scheme that results in more reliable estimates of cloudiness at night. This not only leads to more accurate daily averages, but, more significantly, leads to a more reliable determination of diumal cycles than has been obtained previously from surface observations on a global scale.

\section{DATA SOURCE AND ANALYSIS}

\section{A. Data Sources}

For land stations, synoptic weather reports were obtained from the National Meteorological Center (NMC). Only those stations which have been assigned official station numbers by the World Meteorological Organization (WMO) were utilized. About 124 million reports were available for cloud analysis for the 10-year period December 1981 through November 1982 (referred to as 1982-91). Synoptic reports are recorded 8 times per day: 00, 03, 06, 09, 12, 15, 18, 21 GMT. However, many stations report only every 6 hours (notably those in the United States and Australia), some less often, and some only during the daytime.

Ship reports were obtained from the Comprehensive Ocean-Atmosphere Data Set (COADS), Interim Product CMR5 Reports (Woodruff et al., 1987). There were 14.4 million reports available for cloud analysis over the oceans.

\section{B. Data Analysis}

\section{1) Processing of Weather Reports.}

Synoptic weather reports are coded according to the system given by the World Meteorological Organization (WMO, 1988). The information in these reports that relates to cloud analysis is summarized in Table 1. For the total cloud and weather type analyses reported here, only N, ww, and 
$I_{x}$ are of direct relevance. However, $N_{h}, C_{L}, C_{M}$ and $C_{H}$ were used in error checking. Definitions of the cloud and weather types analyzed here are given in Table 2.

The flow chart in Figure 1 shows the processing and quality control checks performed on each weather report read from the original archives (NMC or COADS). The percentage of reports discarded at each stage of the processing is indicated. Land and ship reports required slightly different checks in the early stages of processing but were treated identically below the horizontal dashed line in the upper portion of the figure. If a land station did not have a WMO station number it was discarded (many of these were from the United States), thus ensuring more uniformity in reporting procedures. If a ship report was known to be from a buoy (from the "deck" number in the COADS data) it was discarded. Any report that had no cloud information $(\mathrm{N}=l)$ was discarded.

In 1982 WMO introduced several coding procedure changes (WMO, 1988). One of these changes now instructs observers to set $w w=/$ if present weather was either "not available" or "observed phenomena were not of significance" (ww codes 00-03 are considered to represent phenomena without significance). The present weather indicator, $I_{x}$, is used to distinguish these cases. Land station reports with $I_{2}$ values of 4,5 or 6 signify automatic weather stations and were discarded. Reports with $\mathrm{I}_{\mathrm{x}}=3$ (data not available) were also discarded because without ww it is not possible to interpret cases of $\mathrm{N}=9$ (see Warren et al., 1986) or to evaluate the occurrence of precipitation. $\mathbf{I}_{x}=2$ indicates that observed phenomena were not of significance, while $I_{x}$ is coded as " 1 " when ww is given. Occasionally $I_{x}=1$ when $w w=/$. These inconsistent reports were also discarded.

Examination of the NMC data set showed that while land station reports conformed to this new coding procedure almost immediately, ship reports did not incorporate $\mathrm{I}_{\mathrm{x}}$ coding consistently until 1985. The COADS data set does not even contain $I_{x}$. Thus some ship reports that should be discarded on the basis of $I_{x}$ were kept. At the horizontal dashed line in Figure 1 there were 125 million land reports and 15.8 million ship reports remaining. The discard fractions below the line are fractions of these numbers.

If the sky was obscured due to fog ( $1.1 \%$ land, $2.5 \%$ ship), thunderstorms $(0.05 \%$ land, $0.17 \%$ ship), or rain/snow ( $0.4 \%$ land, $1.1 \%$ ship), the sky was considered to be overcast $(\mathrm{N}=8)$. This source of "cloudiness" contributed about $1 \%$ to the total cloud cover globally, and much more in some locations and seasons (Hahn et al., 1992).

Other data consistency checks are indicated in the figure. The final one tests whether the reported latitude and longitude of a land station puts the station on water (rare) or whether reported latitude and longitude of a ship puts the ship on land $(1.3 \%)$. The reports that survive these tests (124.2 million for land and 14.4 million for ships) are used to compute total cloud cover and the frequencies of occurrence of clear sky, fog, and precipitation. Cloud types were not analyzed further in this study.

\section{2) Determination of Cloudiness at Night.}

The ability of surface observers to adequately detect clouds at night has been questioned for many years (e.g. Riehl, 1947; Schneider et al., 1989). In an attempt to find a practical solution to this "night-detection-bias", the authors (Hahn et al., 1994) analyzed ten years of nighttime data for the zone $0-50^{\circ} \mathrm{N}$ and plotted reported cloud cover as a function of the illumination due to moonlight. The illuminance function used by the authors depends on the phase and altitude of the moon and on the distance of the moon from the earth. It was found that the amount of total cloud reported at night increased as the illuminance of the moon increased up to a certain threshold, after which reported 
cloud amounts leveled off. This threshold is referred to as "the illuminance criterion" and corresponds to the light produced by the twilight sun at an altitude of about 9 degrees below the horizon. Thus the illuminance criterion is met when either the sun is at an altitude greater than $-9^{\circ}$ or the position of the moon is such that its illuminance exceeds the threshold. These conditions can be determined for each report with the use of an ephemeris and the latitude, longitude, and time of the report.

By using only reports for which the illuminance of the moon (or sun) exceeded the threshold illuminance, we can obtain more reliable estimates of nighttime cloudiness than have been previously obtained from surface observations. Application of the illuminance criterion increases the computed global average total cloudiness at night by about $4 \%$ and thus increases the daily average cloudiness by about $2 \%$. There is also a significant effect on computed diurnal cycles which will be demonstrated in Section 3.

This illuminance criterion was applied in the analyses of total cloud cover and clear-sky frequency archived here, but not for fog and precipitation whose detection does not depend on illumination. (For comparative purposes, some analyses of total cloud and clear sky were also performed utilizing all observations as described in Section 3.) Application of the illuminance criterion caused $27 \%$ of the land reports and $24 \%$ of the ship reports to be discarded, leaving 90.4 million reports for land and 10.9 million reports from ships.

\section{3) Averaging Methods.}

An average for a synoptic hour, or for daytime or nighttime only, was obtained simply by averaging all the contributing reports, whether for a single year or a multi-year average. Because many nighttime reports are discarded due to the illuminance criterion, there are far fewer contributing reports at night than during the daytime. Therefore, to obtain the "daily" average, daytime and nighttime averages are first determined separately and then averaged together. For this purpose, daytime is considered to be 06-18 local time (determined from the longitude at the center of the grid box in which the observation was made) and nighttime is considered to be 18-06 local time. A daily average was obtained by this method if there were at least 50 observations contributing to both the day- and nighttime averages. If there were less than 50 observations at night (day) but 100 or more for the daytime (night), then only the daytime (nighttime) observations were used for the average. Otherwise averages were obtained by using all available observations, regardless of time of day. This method was applied uniformly over the globe, even though the method loses significance near the poles. (The poles themselves were considered to be on Greenwich Mean Time.) The particular method used in computing an average is coded in the data record which is described in Section 3.

It should be noted that in a single month at a single point on earth the moon will be above the horizon at night only for about 2 weeks. Thus a nighttime average for a single month, when the illuminance criterion has been applied, will not be fully representative of that month. Longer term averages will be statistically more reliable. For this reason, monthly mean daily averages are not provided in this data archive, although the data for obtaining them are available in the "monthly means by synoptic hour" that are provided (Section 3 ).

\section{Grid Sizes}

The globe was divided into grid boxes for which the various cloud quantities were computed. The three grid sizes used in these analyses are, nominally: $2.5^{\circ} \times 2.5^{\circ}, 5^{\circ} \times 5^{\circ}$, and $10^{\circ} \times 20^{\circ}$ latitude $\mathrm{x}$ longitude. Because the area contained within a $5 \times 5^{\circ}$ box, for example, decreases with 
increasing latitude, boxes poleward of $50^{\circ}$ latitude were made to encompass a wider longitude range such as $5 \times 10^{\circ}$ or $5 \times 20^{\circ}$, etc. A "c" is used to symbolize this condensation or contraction. Thus $5 \times 5 \mathrm{c}$ (or $5 \mathrm{c}$ for short) means $5 \times 5^{\circ}$ between $50 \mathrm{~N}$ and $50 \mathrm{~S}$ but a larger longitude width poleward of $50^{\circ}$ latitude. The three grid sizes used are described in Table 3.

Each grid box is assigned a number. The numbering goes from west to east (beginning with the Greenwich Meridian) and north to south. The west and south borders of a box are considered to be within the box $\left(90^{\circ} \mathrm{N}\right.$ is also considered to be within box 1). The latitude and longitude at the center of each numbered box for each grid are given in this archive (Section 3 ).

The $5 \mathrm{c}$ grid is used for most analyses over the ocean and for some land analyses. The $10 \mathrm{c}$ grid is used for some ocean analyses because relatively sparse ocean data make some analyses at the smaller grid size unreliable. The $2 \mathrm{c}$ grid is used only for analyses over land where finer resolution is practical.

\section{CONTENTS AND ORGANIZATION OF THE DATA ARCHIVE}

\section{A. General}

The data are divided into 15 files, numbered 2 to 16 as shown in Table 4. File 1 is a brief documentation of the archive, containing excerpts from this report. The organization of data into files is based on similarity of content and data format. Total cloud data are generally separated from weather type data. Land and ocean data are generally in separate files as well. There are many grid boxes that contain both land and ocean, and two separate values are retained in this way. The user can combine the two if desired, although land and ocean values are given at different grid scales making suitable averaging necessary. File 3 contains land and ocean data merged on a $5 \mathrm{c}$ grid for selected long-term averages (see below). The files listed with the same group cluster name would logically belong within the same file. However, monthly averages by synoptic hour require so much storage space that they are placed in separate files.

A detailed breakdown of the contents of each data file is given in Table 5. Each data file contains a series of "map groups", each of which consists of gridded data for total cloud or weather type averages for a particular season or year or time of day or for grid information (File 2) as indicated in the table. A map group is made up of the data records for a number of grid boxes over the globe and a header record which identifies the group:

Header record identifying map group

Data record for first reported box

Data record for second reported box

etc. for number of boxes specified in header.

This pattern is repeated throughout each file in the order indicated in Table 5. Data record formats shown in Table 6 and the header record described in Table 7 are discussed in the next section.

The number of data records within a map group depends on the grid size and whether it is for land or ocean. Since there would be no land data in an ocean-only grid box (and vice versa), data records for such boxes are uniformly not written. (Box numbers based on the full grid are provided in the data record itself.) The numbers of boxes given within each type of map group are listed in a 
footnote to Table 5 (and are coded in the header record). Thus, in File 6, for example, each ocean 5c map group contains 1494 logical records - a header record and 1493 data records, while a land 5c map group in File 4 contains a total of 862 logical records. While there are actually $9345 \mathrm{c}$ boxes with land fractions greater than 0.0001 (and 27 additional boxes with reporting stations on small islands), only 861 boxes have data for the period analyzed here and only those boxes are archived. Similarly there are $30272 \mathrm{c}$ boxes with land fractions $>0.0001$ (and 48 additional boxes with reporting stations on small islands) but only 2309 boxes have data. The $10 \mathrm{c}$ grid contains so few boxes that it is convenient to retain all 230 boxes, including the 16 land-only boxes. In file 3 , where land and ocean are combined on a $5 \mathrm{c}$ grid, all 1820 boxes are retained.

\section{B. Details of Organization}

The use of Table 5, along with Tables 6 and 7, should enable the user to find any desired quantity, once a few conventions are understood. Abbreviations used are listed alphabetically in Table 8.

\section{1) Map Groups and Data Formats.}

Each data file shown in Table 5 is a series of map groups which are numbered consecutively within each group cluster. Each group contains the data relevant to the cloud or weather type quantities listed under the contents heading. These data are given for each reported grid box according to the indicated data format which is described in Table 6. For example, group 2 in File 6 contains data relevant to mean seasonal (DJF, 1982-91) total cloud cover over ocean on a 5c grid. These data are organized according to format 22. Table 6 shows that format 22 specifies the box number, the number of observations, the average amount of total cloud (given to hundredths of a percent), the standard deviation of the observations contributing to the average (given to tenths of a percent), and indicator telling whether contributing observations were from daytime, nighttime, or both (see IDN in Table 8), an indicator telling whether the observations were from land stations or ships, and the number of seasons contributing to the average (relevant only for annual averages).

Data format numbers are given as 2-digit integers. The tens digit distinguishes 5 data classes as shown in Table 6 . The units digit is used to distinguish some small difference in the meaning of a variable represented. Format 40 is used to distinguish the fact that the phase of the annual harmonic is given in units of months as opposed to hour for the diurnal harmonic in formats 41 and 42 . The differences between formats 41 and 42 (as well as 51 and 52) are simply that the data variables refer to amount or frequency, respectively. While these distinctions (and that between formats 22 and 32) are not essential in this "Total Cloud Edition", these numbers are retained to be consistent with our previous archive (Hahn et al., 1988) and a possible future archive containing cloud type data.

The order in which the groups follow each other, with respect to season, time of day, year or weather type, can also be determined from Table 5. Where there are simply 4 seasons (or 12 months) as with File 4 groups 2-5 (or 42-53), all the boxes for the first season (or month) are followed by the next group header and all the boxes for the second season (or month) and so on. The order in which the seasons are given is DJF, MAM, JJA, SON; months are given in the order Dec, Jan, Feb, ... Nov. In cases such as for File 4 groups 10-41 or 98-137 where more than one time or year is given for each season, the convention adopted is to increment the parameter listed first while holding the parameter listed second constant. Thus the order for groups 10-41 would be 8 synoptic hours (in order of increasing hour) for DJF, then 8 synoptic hours for MAM, etc. The order for groups 98-137 would be 4 seasons for 1982,4 seasons for 1983 , etc. Thus the individual seasons follow each other 
chronologically. The order in which weather type groups (as in File 8) follow each other is the numerical order of the numeric codes shown in Table 7. Using the convention of incrementing the leftmost group parameter first, it can be determined, for example, that the group number for precipitation frequency over land for MAM 1982-91 at 03 GMT is 69.

\section{2) Group Headers.}

The first record in each map group is a header record which identifies the group. The format of this header record is shown in Table 7. The first parameter of the header record gives the map group number. These numbers have no special significance other than that they run sequentially through a group cluster (Tables 4 and 5) and may aid in locating or identifying a map group.

The next three parameters specify the number of boxes reported in the group (the number of records to be read before reaching the next map group; this number may be less than the total number of boxes in a grid as discussed above), the grid size of the boxes, and whether the data are for land or ocean or both. This latter parameter, LO, differs from the parameter LOB in Table 6 in that LO specifies the intent of the map group while LOB indicates the actual condition for a particular box.

The IMOON parameter indicates whether the illuminance criterion was applied in the analysis of the data for the group. The last 5 parameters in the group header indicate the year, season (or month), time of day, cloud or weather type to which the data refer, and the data format.

Even without the map group number, the other 9 parameters together uniquely define each map group. The map group headers, along with example data records, that correspond to the examples given in the last section from Files 6 and 8 are:
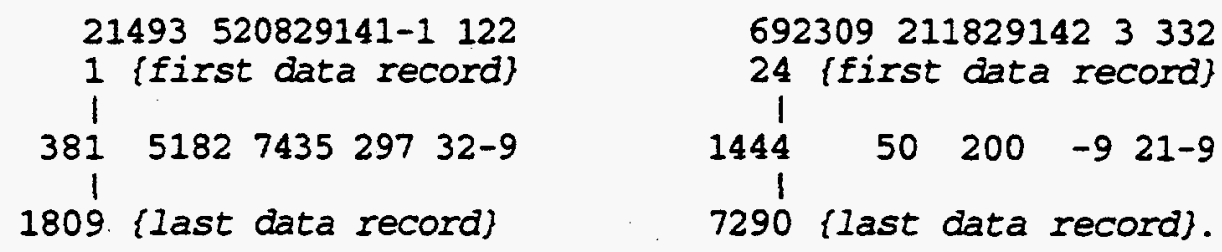

The first example is for daily-average total cloud cover over the ocean with the illuminance criterion applied for DJF, 1982-91. There are 1493 data records in this $5 \mathrm{c}$ map group. The first data record is for box 1 and the last is for box 1809. The example box 381 (in the eastern North Pacific) has 5182 observations with an average of $74.35 \%$ total cloud cover. The standard deviation of the observations is $29.7 \%$. The daily average was obtained by averaging daytime and nighttime averages. Only ship data contributed. The "-9" signifies that no value is reported for the last variable, NSN (see The Missing Value Code on page 15).

The second example is for the frequency of occurrence of precipitation over land at 03 GMT for MAM, 1982-91. The illuminance criterion was not applied. There are 2309 data records in this $2 \mathrm{c}$ map group. The first data record is for box 24 and the last is for box 7290 . The example box 1444 (in the westem United States) had only 50 observations during this time, giving an average precipitation frequency of $2.00 \%$. The standard deviation is not given. These data are for nighttime over land. 


\section{Details of Contents}

All data on this tape were written as integers. Floating point quantities were multiplied by a power of 10 and rounded off to give an integer. When read using the specified formats shown in Table 6 , the proper floating point values are recovered. This was demonstrated with the examples given in the last section. Cloud cover and frequencies are given as percent. These and the units of other variables defined in the data formats are defined in Table 8.

After discussing the missing value code, details or peculiarities of the contents of each data file will be discussed. Refer to Tables 5, 6 and 7 for references to file contents, format numbers and header coding, respectively. Any non-standard terms not defined in the text can be found in Tables 1 , 2,3 or 8 .

\section{1) The Missing Value Code.}

Any data variable for which no value is reported is assigned the "missing value code", which was chosen to be -9 . Thus, when reading in the various floating point notations, the actual value obtained may vary but will always be less than 0 . The trend (File 16 , formats $51 \& 52$ ) is the only data variable for which a negative value is valid. Thus for trends the missing value code should be considered to be NYRS $=0$. Note that any time NOBS is zero, data variables such as AMT, FQ or SD will be assigned the missing value code, but it is possible for data variables, such as SD, to be assigned the missing value code even when NOBS is not zero.

\section{2) File 2: Grid Information; format 10.}

The three groups in this file contain data related to the grids used for dividing the globe (see Table 3). The parameters YEAR, SN, TIME and TYPE in the group header are set to -9 . Inclusion of the box number in this data format is redundant since here all boxes are reported and data records are in box number order. The latitude ( 90 to -90 for $N$ to $S$ ) and longitude ( 0 to $360 \mathrm{E}$ ) of a box center are given to two decimal places. Since the gridded data in all subsequent files are identified only by box number, the information here allows those data to be located on a map. The inverse relation (converting latitude and longitude to box number) can be achieved with a simple mathematical relationship (Hahn et al., 1988). The fraction of each grid box that is land is given to four decimal places. Here "land" means "not ocean" since lakes and ice shelves are counted as land. The method for determining these fractions and a map for the $5 \mathrm{c}$ grid are given in Warren et al. (1986). Ocean fraction is 1 - land fraction.

The number of land stations in a $2 \mathrm{c}$ box was approximated by taking the number of observations over the 10-year period for a single season (MAM) for either 00 or $12 \mathrm{Z}$, whichever was daytime for a box, and dividing by 10 (for the number of years) and by 3 (for the number of months in a season) to get the average number of reports per month at a single reporting time. If each station always reported, there should then be 30 reports per station. Since station reports are sometimes missing, the above number was divided by 25 to obtain an approximate value for the number of stations. This number may be of value in estimating the reliability or representativeness of data within a box. NLSTA is set to -9 in the $5 c$ and $10 c$ data records. 


\section{3) File 3: Land and Ocean Combined; formats 22,32.}

This is the only file in which land and ocean values were merged onto a single grid, and this was done only for 10-year mean values (monthly, seasonal and annual). An average (total cloud cover or weather type frequency), for any grid box for which both land and ocean values contributed, was determined by weighting the contributing land and ocean values by their respective fractional area within the box. Only averages made from 100 or more observations were allowed to contribute. The variables SD and IDN (and NSN for seasonal and monthly averages) were set to -9 in the data record. LOB indicates whether land, ocean, both or neither contributed to the box. For the annual averages, NSN is the sum of the number of seasons that contributed to the land and ocean annual averages before merging, and so can have values 0 to 8 (in this file, -9 is used rather than 0 ). If NSN is 3 to 7 and LOB is 3, it cannot be known how many seasons were contributed by land or ocean without examining the annual map groups for land and ocean separately in their respective files.

NOBS is the sum of the number of observations contributed by land and ocean. For annual averages on a $5 \mathrm{c}$ grid, it is possible for NOBS to be greater than 999999 (the maximum allowed in the I6 format) since some boxes, notably in Europe, have a large number of land stations. NOBS in such cases was set to 999999 . (The actual number can be retrieved, if desired, by adding up the number of observations in the contributing boxes and seasons given in the other files.)

Figures 2-5 are provided to illustrate some of the information available in this archive and serve as examples against which user output can be checked. The first map group of File 3 contains the data for the global distribution of annual average total cloud cover for the 1982-91 period with the illuminance criterion applied. This is shown in Figure 2a. The global distribution of annual average precipitation frequency (from all observations), a quantity not provided in our previous archive, is given in Figure $2 \mathrm{~b}$. These data are contained in map group 3 of File 3. Values are printed in these two figures only where there are at least 100 observations contributing.

\section{4) Files 4-7: Total Cloud Cover; format 22.}

Total cloud cover is given in percent (AMT in format 22). Ten-year means for daily average annual, seasonal and monthly total cloud cover are given on the $2 \mathrm{c}$ grid for land and on the $5 \mathrm{c}$ grid for ocean. Daytime means are given seasonally as well. Because some parts of the southern oceans are poorly sampled (see, for example, Figure $2 a$ ), mean seasonal values over the ocean are also given on the $10 \mathrm{c}$ grid. It is the $10 \mathrm{c}$ grid that is used for the ocean mean seasonal averages by synoptic hour, which are utilized in the diurnal cycle analysis given in File 16. Since land stations are at fixed locations, use of a smaller grid size does not pose the problem that it does for the ocean.

Since previous climatologies, such as our own (Warren et al., 1986; 1988), did not utilize the illuminance criterion, a discontinuity of about $2 \%$ would occur when comparing the present with the previous data. Therefore 10 -year mean seasonal and yearly seasonal mean values were also computed using all observations (File 4 map groups 54-97 and File 6 map groups 58-101). These data also make it possible to analyze the effects of the illuminance criterion in the present data set. Grid sizes of $5 \mathrm{c}$ and $10 \mathrm{c}$ for land and ocean, respectively, were selected for ease of comparison with our previous data set (Hahn et al., 1988). 
Seasonal means are given for daytime and nighttime values as well as for the daily averages to aid in analysis of possible differences in trends between day and night. Seasonal means for land are given at $5 \mathrm{c}$ as well as $2 \mathrm{c}$ to make merging with ocean values easier if desired.

The most basic units provided in this data set are the monthly means by synoptic hour. From these, all other averages given, and some not given, can be reconstructed. Since it requires 960 map groups for 10 years of 8 synoptic hours monthly, this unit is provided in a file separate from the rest of the group cluster. The IDN variable in the data record labels each GMT synoptic hour for each box as day or night.

The mean annual total cloud for a grid box was computed by averaging the mean seasonal values of the seasons with 100 or more observations. The number of seasons contributing to the annual average is entered in the NSN variable and may vary from 0 to 4 . Note that if NSN is 1 , as may be true for ocean boxes near the poles, the reported value may not be representative of the true annual value. NOBS is the sum of the number of observations in the contributing seasons. SD and IDN are set to -9 . For seasonal and monthly averages, only NSN was uniformly set to -9 .

\section{5) Files 8-15: Weather Types; format 32.}

Most of the comments made in the last section apply equally well here. A few differences are noted. Percent frequencies of occurrence of clear sky, precipitation and fog are given in these files. The SD variable in the data record is assigned the missing value code. Precipitation and fog are always computed from all observations and so do not have to be repeated in the "all" map groups. However, since fog is given on the $2 c$ grid for land, it is repeated at $5 c$ for ease of comparison with previous data sets. Daytime and nighttime seasonal means are not given here (but could be reconstructed from the monthly means by synoptic hour if desired). This is also true for seasonal means at $5 \mathrm{c}$ for land. Seasonal means for the ocean are given on the $10 \mathrm{c}$ grid.

\section{6) File 16: Harmonics, Interannual Variations and Trends; formats 40-42, 51-52.}

The unifying feature of the contents of this file is that these are quantities derived from data already given in the archive. Separate land and ocean values are included and two different format types are used to accommodate the harmonic analyses on the one hand and the interannual variations on the other.

The phase and amplitude of the annual harmonic of total cloud cover (or of the frequency of occurrence of a weather type) were computed from the mean monthly values if all 12 months had 100 or more observations. (NT in format 40 always gives the number of months with 100 observations but the other variables were only computed if NT=12.) The amplitude reported is the absolute amplitude so that, for example, if the mean value for a particular cloud amount is $25 \%$ and the maximum of the fitted cycle is $30 \%$ then the amplitude is reported as $5 \%$ (rather than $20 \%$ which would be the normalized amplitude). The phase is a numeric value that corresponds to a month such that 1.0 is the middle of January, 2.0 is the middle of February, etc. Phase values reported range from 0.5 to less than 12.5. The value 0.0 (rather than -9) was used for PHASE in cases in which the amplitude was exactly zero (thus distinguishing these from "missing value" cases). AVG is the average of the 12 months used in the analysis and may differ somewhat from the annual values given in the other files 
because of the different averaging methods. VAF is the percent of the variance accounted for by the amplitude of the annual harmonic.

To exemplify some features of the annual harmonic, figures 3a-c give the geographic distribution of the phase of the annual harmonic for total cloud cover, precipitation frequency and fog frequency, respectively, from the ocean map groups 21, 23 and 24 of File 16. (A phase of " 0 ", common for fog in Figure 3c, indicates that the amplitude is exactly zero.) It is interesting to note that maximum total cloud cover occurs during the summer months in the North Pacific (Figure 3a), while precipitation frequency reaches maximum values during the winter months (Figure $3 b$ ). Figure $3 c$ shows that fog is at a maximum in this region during the summer. The amplitude of the annual cycle for fog (available in the data record but not shown here) reaches $10-20 \%$ in the western North Pacific, making a significant contribution to the computed total cloud cover in this region during the summer. By comparison, amplitudes for the fog annual cycle are generally near zero between $30 \mathrm{~N}$ and $50 \mathrm{~S}$ over the ocean.

The diurnal harmonic (formats 41-42) was computed from the mean seasonal by-synoptic-hour values if there were 8 or 4 evenly spaced hours with 100 or more observations. If these conditions were met then NT $=8$ or 4 , otherwise NT was set to 0 and the other variables were set to -9 . The amplitude reported is the absolute amplitude (not the normalized amplitude). The phase is the hour of day (mean solar time of the box center) and may range from 0 to less than 24 . Since zero is a valid phase here, PHASE was set to -9 for cases in which the amplitude was exactly zero. AVG is the average of the 8 or 4 hours used in the analysis and may differ somewhat from the seasonal values given in the other files because of the different averaging methods. VAF is the percent of the variance accounted for by the amplitude of the diurnal harmonic.

As might be expected, the utilization of the illuminance criterion had a profound effect on the outcome of the diurnal cycle analysis. The geographic distribution of the amplitude and phase of the diumal harmonic for total cloud cover over the oceans is shown on a $10 \mathrm{c}$ grid between $60 \mathrm{~N}$ and $60 \mathrm{~S}$ for four seasons in Figures 4a-d. (The phase is printed in these figures only where the amplitude is not zero.) The effect of the illuminance criterion is apparent when comparing these figures to Maps 114-115 of Warren et al. (1988) which show near-noon phases dominating in the diumal analysis presented for 1954-1983 data without application of the illuminance criterion. For example, for JJA, in Figure $4 \mathrm{c}$, a band of midnight to $5 \mathrm{AM}$ phases evident in the eastern Pacific replaces $4 \mathrm{AM}$ to early afternoon phases in that same region shown in Map 115b of Warren et al. Early aftemoon phases are still evident in the western North Pacific and the western North Atlantic, however.

Diumal cycle analysis for land data is given on the $2 c$ grid. Since it is difficult to display the entire $2 c$ grid, examples are given for two selected mid-latitude regions in Figure 5. Figure 5a shows the diumal cycle of total cloud cover for part of Asia for DJF. Here diumal sampling tends to be 8 times per day and there tend to be many reporting stations, particularly in China in the southeast portion of the region. While phase differences between these data and those of Warren et al. (1986, Maps 18-19) tend not to be as dramatic as those over the ocean, the moming phases on the northwest and southeast portions of Figure 5a contrast with those of Warren et al. Where the phases are comparable (and near noon), however, the amplitudes tend to be smaller when the illuminance criterion is applied.

Figure $5 \mathrm{~b}$ shows the diumal cycle analysis for JJA for the region of North America that covers most of the United States, where diurnal sampling tends to be 4 times per day. In the eastern portion of the region phases tend to have early aftemoon values, in agreement with those of Warren et al. 
(1986, Maps 22-23), while in the westem portion the phases are more variable. This illustrates another feature of the present data set. The $2.5 \times 2.5^{\circ}$ resolution is capable of resolving features that are missed at $5 \times 5^{\circ}$, such as the band of late night to early moming phases evident in the central plains of the United States.

The last map groups in this file contain the results of the analysis of interannual variations and trends. For each season, an individual year contributed to the computation of IAV, TRND and UNC (formats 51-52) for a grid box if there were at least 100 observations. The number of years contributing is given in the variable NYRS. SPAN gives the number of years between the first and last years contributing, including the first and last years. If NYRS (also SPAN) is zero, IAV, TRND and UNC are assigned the value -9. IAV is the standard deviation of the contributing yearly values about the multi-year mean. TRND is the slope of the straight line which was fit to the data points by least-squares analysis and is given in units of percent cloud amount (or percent frequency) per year. UNC is the uncertainty of the slope (Bevington, 1969, page 113) in the same units.

\section{HOW TO OBTAIN THE DATA}

This documentation and the data described herein are available from:

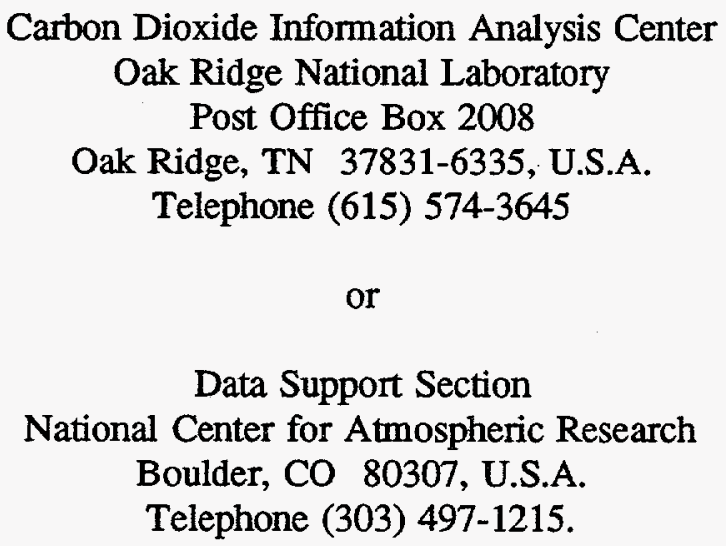

The following citation should be used for referencing this archive and/or this documentation report:

Hahn, C.J., S.G. Warren, and J. London, 1994: Climatological Data for Clouds Over the Globe from Surface Observations, 1982-1991: The Total Cloud Edition. NDP026A, Carbon Dioxide Information Analysis Center, Oak Ridge National Laboratory, Oak Ridge, TN. (Also available from Data Support Section, National Center for Atmospheric Research, Boulder, CO.)

Note that the archive of our earlier climatology (Hahn et al., 1988), along with accompanying atlases (Warren et al., 1986, 1988), is available from the same sources listed above.

\section{ACKNOWLEDGEMENTS}

This work was supported by NASA Grant NAG-1-998 and by Battelle Pacific Northwest Laboratories, Atmospheric Radiation Measurement Program (Contract 144806-A-Q1). We would also like to acknowledge the long term cooperation and the provision of computing facilities made 
available to us from the Scientific Computing Division of the National Center for Atmospheric Research.

\section{REFERENCES}

Bevington, P.R. 1969: Data Reduction and Error Analysis for the Physical Sciences, McGraw-Hill, $336 \mathrm{pp}$.

Hahn, C.J., S.G. Warren, J. London, and R.L. Jenne, 1988: Climatological Data for Clouds Over the Globe from Surface Observations. NDP-026, Carbon Dioxide Information Analysis Center, Oak Ridge National Laboratory, Oak Ridge, TN. (Also available from Data Support Section, National Center for Atmospheric Research, Boulder, CO.)

Hahn, C.J., S.G. Warren, and J. London, 1992: The use of COADS ship observations in cloud climatologies. Proceedings of the International COADS Workshop, H.F. Diaz, K. Wolter, and S.D. Woodruff, Eds., NOAA/ERL, Boulder, CO, 271-280.

Hahn, C.J., S.G. Warren and J. London, 1994: The effect of moonlight on observation of cloud cover at night, and application to cloud climatology. Journal of Climate, Accepted.

Riehl, H., 1947: Diumal variation of cloudiness over the subtropical Atlantic Ocean. Bulletin of the American Meteorological Society, 28, 37-40.

Schneider, G., P. Paluzzi and J.P. Oliver, 1989: Systematic error in the synoptic sky cover record of the South Pole. Journal of Climate, 2, 295-302.

Warren, S.G., C.J. Hahn, J. London, R.M. Chervin and R.L. Jenne, 1986: Global distribution of total cloud cover and cloud type amounts over land. NCAR Technical Note TN-273+STR, Boulder, CO, 29 pp. + 200 maps (also DOE/ER/60085-H1).

Warren, S.G., C.J. Hahn, J. London, R.M. Chervin and R.L. Jenne, 1988: Global distribution of total cloud cover and cloud type amounts over the ocean. NCAR Technical Note TN-317+STR, Boulder, CO, 42 pp. + 170 maps (also DOE/ER-0406).

Woodruff, S.D., R.J. Slutz, R.L. Jenne and P.M. Steurer, 1987: A comprehensive ocean-atmosphere data set. Bulletin of the American Meteorological Society, 68, 1239-1250.

World Meteorological Organization, 1988: Manual on Codes, Volume 1. ( WMO Publ. No. 306), WMO, Geneva. 
Table 1. Cloud Information Contained in Synoptic Weather Reports

\begin{tabular}{lll}
\hline Symbol & Meaning & Codes* \\
\hline $\mathrm{N}$ & total cloud cover & $\begin{array}{l}0-8 \text { eighths } \\
9=\text { sky obscured }\end{array}$ \\
& & $0-8$ eights \\
$\mathrm{N}_{\mathrm{h}}$ & lower cloud cover & $0-9$ \\
$\mathrm{~h}$ & lower cloud base height & $0-9$ \\
$\mathrm{C}_{\mathrm{L}}$ & low cloud type & $0-9$ \\
$\mathrm{C}_{\mathrm{M}}$ & middle cloud type & $0-9$ \\
$\mathrm{C}_{\mathrm{H}}$ & high cloud type & $00-99$ \\
$\mathrm{wW}_{\mathrm{N}}$ & present weather & $1-6$ \\
$\mathrm{I}_{\mathrm{x}}$ & present weather indicator & \\
\hline
\end{tabular}

" Any category for which information is lacking to the observer is coded as " $/$.

Table 2. Cloud and Weather Type Definitions Used in Total Cloud Edition

\begin{tabular}{lll}
\hline $\begin{array}{l}\text { Shorthand } \\
\text { notation }\end{array}$ & Meaning & Synoptic codes \\
\hline Tcc & Total cloud cover & $\mathrm{N}=0-9$ \\
Clr & Clear sky & $\mathrm{N}=\mathrm{O}$ \\
$\begin{array}{l}\text { Ppt } \\
\text { (R) }\end{array}$ & $\begin{array}{l}\text { Precipitation } \\
\text { rain or snow } \\
\text { thunderstorm }\end{array}$ & $\mathrm{ww}=50-75,77,79,80-99$ \\
Fog $(\mathrm{F})$ & $\begin{array}{l}\text { Sky obscured due } \\
\text { to fog }\end{array}$ & $\mathrm{N}=9$ with $\mathrm{ww}=10-12$ or $40-49$ \\
\hline
\end{tabular}


Table 3. Grid Box Sizes

\begin{tabular}{|c|c|c|c|c|}
\hline $\begin{array}{l}\text { Box size } \\
\text { (shorthand) }\end{array}$ & $\begin{array}{l}\text { Dimensions } \\
\text { lat } x \text { lon } \\
\text { degrees }\end{array}$ & Latitude range & $\begin{array}{l}\text { Numl } \\
\text { zone }\end{array}$ & $\begin{array}{l}f \text { boxes in } \\
\text { globe }\end{array}$ \\
\hline $\begin{array}{c}2.5 \times 2.5 c \\
(2 c)\end{array}$ & $\begin{array}{l}2.5 \times 2.5 \\
2.5 \times 5 \\
2.5 \times 10 \\
2.5 \times 20 \\
2.5 \times 40 \\
2.5 \times 360\end{array}$ & $\begin{array}{l}50 \mathrm{~N} \text { to } 50 \mathrm{~S} \\
50 \text { to } 70 \\
70 \text { to } 80 \\
80 \text { to } 85 \\
85 \text { to } 87.5 \\
87.5 \text { to } 90\end{array}$ & $\begin{array}{r}144 \\
72 \\
36 \\
18 \\
8 \\
1\end{array}$ & 7290 \\
\hline $\begin{array}{r}5 \times 5 c \\
(5 c)\end{array}$ & $\begin{array}{l}5 \times 5 \\
5 \times 10 \\
5 \times 20 \\
5 \times 40 \\
5 \times 360\end{array}$ & $\begin{array}{l}50 \mathrm{~N} \text { to } 50 \mathrm{~S} \\
50 \text { to } 70 \\
70 \text { to } 80 \\
80 \text { to } 85 \\
85 \text { to } 90\end{array}$ & $\begin{array}{r}72 \\
36 \\
18 \\
9 \\
1\end{array}$ & 1820 \\
\hline $\begin{array}{r}10 \times 20 c \\
(10 c)\end{array}$ & $\begin{array}{l}10 \times 20 \\
10 \times 40 \\
10 \times 60 \\
10 \times 360\end{array}$ & $\begin{array}{l}50 \mathrm{~N} \text { to } 50 \mathrm{~S} \\
50 \text { to } 70 \\
70 \text { to } 80 \\
80 \text { to } 90\end{array}$ & $\begin{array}{r}18 \\
9 \\
6 \\
1\end{array}$ & 230 \\
\hline
\end{tabular}


Table 4. File Information (Total Cloud Edition)

\begin{tabular}{|c|c|c|c|c|c|}
\hline File & $\begin{array}{l}\text { Group } \\
\text { cluster } \\
\text { name }\end{array}$ & $\begin{array}{l}\text { General } \\
\text { contents }\end{array}$ & $\begin{array}{l}\text { Logical } \\
\text { records }\end{array}$ & $\begin{array}{l}\text { Characters } \\
\text { per record }\end{array}$ & Characters \\
\hline 1 & RDME & README (brief documentation) & 452 & 80 & 36,160 \\
\hline 2 & LLFR & $\begin{array}{l}\text { Latitude, Longitude, } \\
\text { Land-fraction \& Number } \\
\text { of land stations for } \\
\text { grid boxes }\end{array}$ & 9,343 & 24 & 224,232 \\
\hline 3 & TWLO & $\begin{array}{l}\text { Land \& Ocean Combined } \\
\text { total cloud \& weather types }\end{array}$ & 123,828 & $"$ & $2,971,872$ \\
\hline 4 & TCCL & Land Total Cloud Cover & 472,038 & $"$ & $11,328,912$ \\
\hline 5 & TCCL & $\begin{array}{l}\text { Land Total Cloud Cover } \\
\text { by synoptic hour, monthly }\end{array}$ & $2,217,600$ & $"$ & $53,222,400$ \\
\hline 6 & $\mathrm{TCCO}$ & Ocean Total Cloud Cover & 229,134 & $"$ & $5,499,216$ \\
\hline 7 & $\mathrm{TCCO}$ & $\begin{array}{l}\text { Ocean Total Cloud Cover } \\
\text { by synoptic hour, monthly }\end{array}$ & $1,434,240$ & $"$ & $34,421,760$ \\
\hline 8 & WXTL & Land Weather Types - & 720,346 & $"$ & $17,288,304$ \\
\hline 9 & WXTL & $\begin{array}{l}\text { Land Clear-sky Frequency } \\
\text { by synoptic hour, monthly }\end{array}$ & $2,217,600$ & $"$ & $53,222,400$ \\
\hline 10 & WXTL & $\begin{array}{l}\text { Land Precipitation Frequency } \\
\text { by synoptic hour, monthly }\end{array}$ & $2,217,600$ & $"$ & $53,222,400$ \\
\hline 11 & WXTL & $\begin{array}{l}\text { Land Fog(sky-obscured) Freq. } \\
\text { by synoptic hour, monthly }\end{array}$ & $2,217,600$ & $n$ & $53,222,400$ \\
\hline 12 & WXTO & Ocean Weather Types & 156,954 & $n$ & $3,766,896$ \\
\hline 13 & WXTO & $\begin{array}{l}\text { Ocean Clear-sky Frequency } \\
\text { by synoptic hour, monthly }\end{array}$ & $1,434,240$ & $"$ & $34,421,760$ \\
\hline 14 & WXTO & $\begin{array}{l}\text { Ocean Precipitation Freq. } \\
\text { by synoptic hour, monthly }\end{array}$ & $1,434,240$ & $"$ & $34,421,760$ \\
\hline 15 & WXTO & $\begin{array}{l}\text { Ocean Fog(sky-obscured) Freq. } \\
\text { by synoptic hour, monthly }\end{array}$ & $1,434,240$ & $"$ & $34,421,760$ \\
\hline 16 & HIAV & $\begin{array}{l}\text { Harmonics \& Interannual } \\
\text { Variation, land and ocean, } \\
\text { total cloud \& weather types }\end{array}$ & 96,528 & $"$ & $2,316,672$ \\
\hline
\end{tabular}


Table 5. Data Organization

Contents of Surface-based Cloud Climatology Archive, 1982-1991 ${ }^{\#}$ Total Cloud Edition ${ }^{\#}$

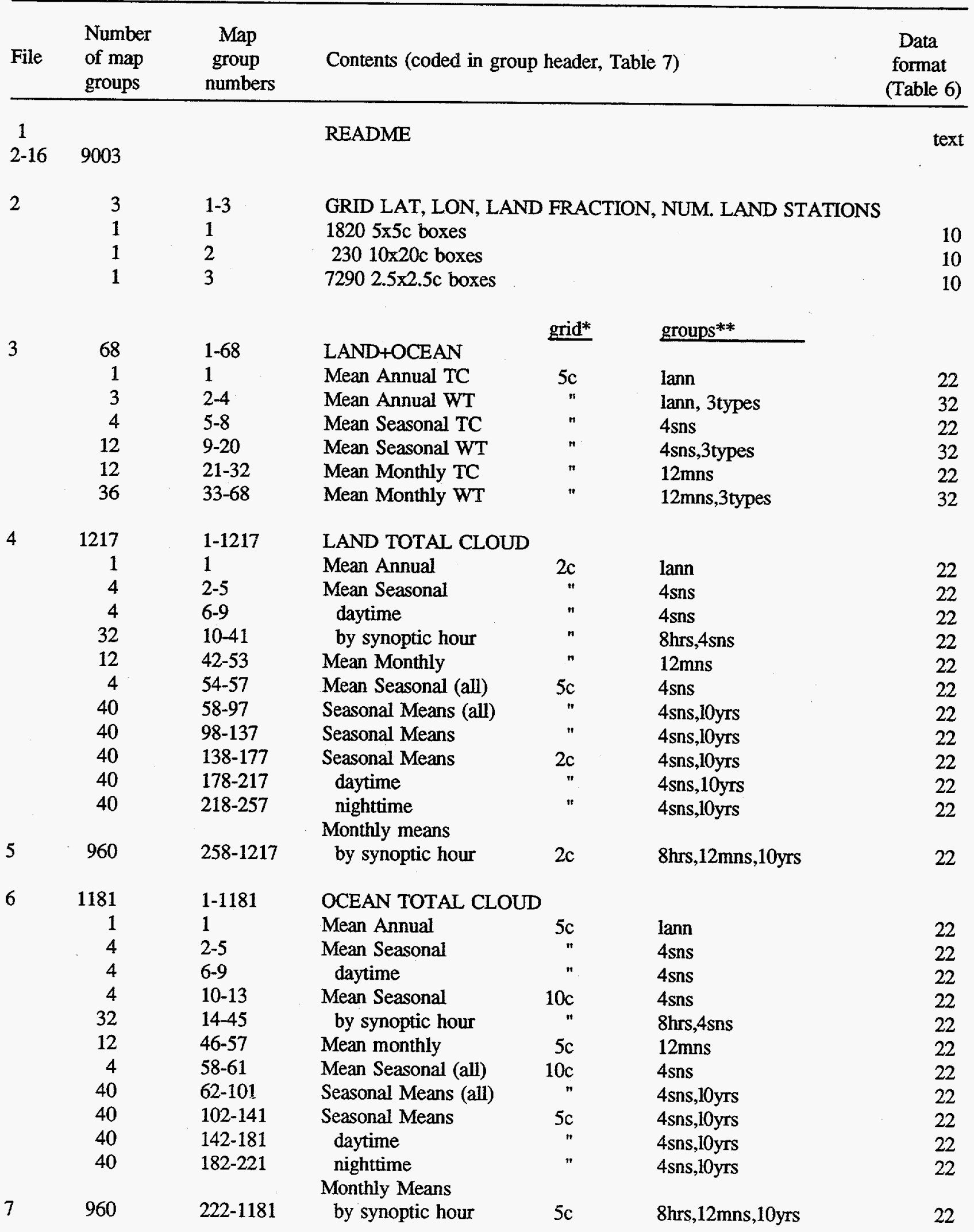




\begin{tabular}{|c|c|c|c|c|c|c|}
\hline \multirow{10}{*}{$\begin{array}{l}\text { File } \\
8\end{array}$} & \multirow{2}{*}{$\begin{array}{l}\begin{array}{l}\text { Number } \\
\text { of map } \\
\text { groups }\end{array} \\
3247\end{array}$} & \multirow{2}{*}{$\begin{array}{c}\begin{array}{c}\text { Map } \\
\text { group } \\
\text { numbers }\end{array} \\
1-3247\end{array}$} & \multicolumn{3}{|c|}{ Contents (coded in group header, Table 7) } & \multirow[t]{2}{*}{$\begin{array}{c}\text { Data } \\
\text { format } \\
\text { (Table 6) }\end{array}$} \\
\hline & & & \multicolumn{3}{|c|}{ LAND WEATHER TYPES } & \\
\hline & 3 & $1-3$ & Mean Annual & $2 c$ & lann,3types & 32 \\
\hline & 12 & $4-15$ & Mean Seasonal & $"$ & 4sns,3types & 32 \\
\hline & 12 & $16-27$ & daytime & $"$ & 4sns,3types & 32 \\
\hline & 96 & $28-123$ & by synoptic hour & " & 8hrs,4sns,3types & 32 \\
\hline & 36 & 124-159 & Mean Monthly & $n$ & $12 \mathrm{mns}, 3$ types & 32 \\
\hline & 8 & $160-167$ & Mean Seasonal (all) & $5 c$ & 4sns,2types & 32 \\
\hline & 80 & $168-247$ & Seasonal Means (all) & $n$ & 4sns, 10yrs,2types & 32 \\
\hline & 120 & $248-367$ & Seasonal means & $2 c$ & 4 sns, 10yrs,3types & 32 \\
\hline $9-11$ & 2880 & $368-3247$ & $\begin{array}{l}\text { Monthly Means } \\
\text { by synoptic hour }\end{array}$ & $"$ & $8 \mathrm{hr}, 12 \mathrm{mn}, 10 \mathrm{yr}, 3 \mathrm{types}$ & 32 \\
\hline \multirow[t]{10}{*}{12} & 3215 & $1-3215$ & \multicolumn{3}{|c|}{ OCEAN WEATHER TYPES } & \\
\hline & 3 & $1-3$ & Mean Annual & $5 c$ & lam, 3types & 32 \\
\hline & 12 & $4-15$ & Mean Seasonal & $"$ & 4sns,3types & 32 \\
\hline & 12 & $16-27$ & daytime & $"$ & 4sns,3types & 32 \\
\hline & 12 & $28-39$ & Mean Seasonal & $10 c$ & 4sns,3types & 32 \\
\hline & 96 & $40-135$ & by synoptic hour & $"$ & 8hrs,4sns,3types & 32 \\
\hline & 36 & $136-171$ & Mean Monthly & $5 c$ & $12 \mathrm{~ms}, 3$ types & 32 \\
\hline & 4 & $172-175$ & Mean Seasonal (all) & $10 \mathrm{c}$ & 4sns ltype & 32 \\
\hline & 40 & $176-215$ & Seasonal Means (all) & $"$ & 4sns:10yrs,ltype & 32 \\
\hline & 120 & $216-335$ & Seasonal Means & $"$ & 4sns, $10 y r s, 3$ types & 32 \\
\hline $13-15$ & 2880 & $336-3215$ & $\begin{array}{l}\text { Monthly Means } \\
\text { by synoptic hour }\end{array}$ & $5 c$ & $8 \mathrm{hr}, 12 \mathrm{mn}, 10 \mathrm{yr}, 3$ types & 32 \\
\hline \multirow[t]{13}{*}{16} & 72 & $1-72$ & \multicolumn{3}{|l|}{ HARMONICS \& IAV } & \\
\hline & 1 & 1 & Annual TC, land & $2 c$ & lann & 40 \\
\hline & 3 & $2-4$ & Annual WT, land & $"$ & lann,3types & 40 \\
\hline & 4 & $5-8$ & Diurnal TC, land & $"$ & $4 \mathrm{sns}$ & 41 \\
\hline & 12 & $9-20$ & Diurnal WT, land & $"$ & 4sns,3types & 42 \\
\hline & 1 & 21 & Annual TC, ocean & $5 c$ & lann & 40 \\
\hline & 3 & $22-24$ & Annual WT, ocean & $5 c$ & lann,3types & 40 \\
\hline & 4 & $25-28$ & Diurnal TC, ocean & $10 c$ & 4 sns & 41 \\
\hline & 12 & $29-40$ & Diurnal WT, ocean & $"$ & 4sns,3types & 42 \\
\hline & 4 & $41-44$ & IAV TC, land & $2 c$ & $4 \mathrm{sns}$ & 51 \\
\hline & 12 & $45-56$ & IAV WT, land & $"$ & 4sns,3types & 52 \\
\hline & 4 & $57-60$ & IAV TC, ocean & $10 c$ & $4 \mathrm{sns}$ & 51 \\
\hline & 12 & $61-72$ & IAV WT, ocean & " & 4sns,3types & 52 \\
\hline
\end{tabular}

* Non-standard terms are defined in Table 8. Briefly: $\mathrm{TC}=$ total cloud; WT= "weather types" (clear sky, precipitation, fog).

\#\# Illuminance criterion applied to total cloud and clear sky unless "all" specified. Ppt and fog always determined from all observations.

* Grid sizes are described in Table 3.

Number of boxes archived for $2 \mathrm{c}$ land $=2309$, for $5 \mathrm{c}$ land $=861$, for $5 \mathrm{c}$ ocean $=1493$, for $5 \mathrm{c}$ land+ocean $=1820$, and for $10 \mathrm{c}$ ocean $=230$

** Months are given in the order: Dec, Jan, Feb,...Nov. If "2types" are specified, they are clear sky and fog. If "1type" is specified, it is clear sky.

Convention for the order of groups in a multigroup listing is: increment left group qualifier while holding right qualifier constant. 
Table 6. List of Formats for Reading Data Records*

(Total Cloud Edition)

Data

class

Format Variables and Format

number

1

Lat, Lon, Land-fraction, Number of land stations

$\begin{array}{llllll}\text { I4 } & \text { F5.2 } & \text { F5.2 } & \text { F5.4 } & \text { I5 }\end{array}$

10 BOX CLAT CLON FRL NLSTA

$2 \quad$ Total Cloud

22

F5.2 F4.1

I2 II I2

BOX NOBS AMT SD IDN LOB NSN

3

32

Weather Types

BOX NOBS

F5.2 F4.1

$\begin{array}{lll}\text { I2 } & \text { I1 } & \text { I2 }\end{array}$

$\begin{array}{ll}14 & 16 \\ \text { BOX } & \text { NOB }\end{array}$

$\mathrm{FQ}$

SD

IDN LOB

NSN

4

Harmonic analyses

$\begin{array}{llllll}\text { I4 } & \text { F5.2 } & \text { F5.2 } & \text { F4.1 } & \text { I2 } & \text { F4.1 }\end{array}$

BOX PHASE AMP VAF NT AVG

40 (for annual harmonic)

41 (for diumal AMT)

42 (for diumal FQ)

5 Interannual variations and trends

$\begin{array}{llllll}\text { I4 } & 12 & \text { I2 } & \text { F5.2 } & \text { F6.3 } & \text { F5.3 }\end{array}$

51

BOX NYRS SPAN IAV

TRND

UNC

(for AMT)

52 (for $F Q$ )

* Terms defined in Table 8.

Data records are 24 characters. 
Table 7. Map Group Header Record Format and Codes* (Total Cloud Edition)

\begin{tabular}{|c|c|c|c|c|c|c|c|c|c|c|}
\hline nat & I4 & I4 & $\mathrm{I} 2$ & I1 & I1 & I4 & I2 & $\mathrm{I} 2$ & $\mathrm{I} 2$ & $\mathrm{I} 2$ \\
\hline neter & MGRP & NBXS & SIZE & LO & IMOON & YEAR & SN & TIME & TYPE & FMT \\
\hline ues & $\begin{array}{r}1 \\
1 \\
3247\end{array}$ & $\begin{array}{r}230 \\
1820 \\
7290 \\
861 \\
1493 \\
2309\end{array}$ & $\begin{array}{r}10 \\
5 \\
2\end{array}$ & $\begin{array}{l}1=\text { Land } \\
2=\text { Ocean } \\
3=\text { Global }\end{array}$ & $\begin{array}{l}0=\text { Moon } \\
1=\text { All }\end{array}$ & $\begin{array}{c}1981 \\
\mid \\
1991 \\
8190 \\
8291\end{array}$ & $\begin{array}{l}0=\mathrm{ann} \\
1=\mathrm{Jan} \\
12=\mathrm{Dec} \\
41=\mathrm{DJF} \\
42=\mathrm{MAM} \\
43=\mathrm{JJA} \\
44=\mathrm{SON}\end{array}$ & $\begin{array}{l}\text {-3night } \\
\text {-2day } \\
-1 \text { daily } \\
00 \text { GMT } \\
03 \\
06 \\
09 \\
12 \\
15 \\
18 \\
21\end{array}$ & $\begin{array}{l}1=\text { TCC } \\
2=\text { CLR } \\
3=\text { PPT } \\
11=F O G\end{array}$ & $\begin{array}{l}10 \\
22 \\
32 \\
40 \\
41 \\
42 \\
51 \\
52\end{array}$ \\
\hline
\end{tabular}

erms are defined in Tables $3 \& 8$. 
AMP

AMT

ann

AVG

BOX

$\mathrm{Cb}$

CLAT

CLON

day (time)

DJF

FMT

FQ

FRL

GMT

IAV

IDN

IMOON

JJA

hrs

lat

LO

LOB

lon
Absolute amplitude of harmonic (not normalized).

Average amount of cloud cover, given in percent.

Annual.

Average AMT or FQ. In formats $40-42$ it is the average of NT values.

Box number specific to grid size. See Table 3.

Cumulonimbus cloud.

Center latitude of grid box. Values +90 to -90 for $N$ to $S$.

Center longitude of grid box. Values 0 to 360 East.

Local time 06-18.

December (of the previous year), January, February.

Data format number (see Table 6).

Frequency of occurrence; given in percent.

Fraction (0. to 1.0000 ) of area in grid box that is land.

Greenwich Mean Time.

Interannual variation (standard deviation of contributing year averages).

Indicates whether reports contributing to box average were from day only $(=1)$, night only $(=2)$, both $(=3)$ or had less than minimum observations $(=4)$ \{see Section $2 \mathrm{~B} 3$ \}.

Indicator for application of the illuminance criterion: $0=$ criterion applied ("Moon"), $1=$ not applied ("All").

June, July, August.

Hours.

Latitude.

Indicator that group data are intended to be for land $(=1)$, ocean $(=2)$, or both $(=3)$.

Indicator that box data were from land only $(=1)$, ocean only $(=2)$, both $(=3)$, or no data $(=0)$.

Longitude. 
Table 8 continued. Terms and Abbreviations Used

\begin{tabular}{|c|c|}
\hline Term & Meaning and description \\
\hline MAM & March, April, May. \\
\hline MGRP & Map group number. Increments serially through group cluster (see Tables $4 \& 5$ ). \\
\hline missing value code & $\begin{array}{l}\text { The integer }-9 \text {. Imerted in data record where no legitimate value is reported. (In formats } 51-52 \\
\text { use NYRS }=0 \text { for missing value code.) }\end{array}$ \\
\hline night (time) & Local time $18-06$. \\
\hline NLSTA & Approximate average number of land stations reporting in a $2 c$ grid box. \\
\hline NOBS & Number of observations. \\
\hline Ns & Nimbostratus cloud. \\
\hline NSN & Number of seasons contributing to annual average. \\
\hline NT & $\begin{array}{l}\text { Number of synoptic hours used ( } 4 \text { or } 8) \text { for diumal harmonic analysis or number of months } \\
\text { used (12) for annual harmonic analysis. }\end{array}$ \\
\hline NYRS & Number of years contributing to trends and IAV. \\
\hline mean seasonal & Long-term average; average over several years for season. \\
\hline Mns & Months. \\
\hline PHASE & $\begin{array}{l}\text { Phase of first harmonic. Diurnal: } 0-24 \text { hours mean solar time of box center }(-9 \text { if } A M P=0) \text {. } \\
\text { Annual: month }(0.5-12.4[1.0=\text { middle of January, etc. }] ; 0 \text { if } A M P=0) \text {. }\end{array}$ \\
\hline SD & Standard deviation; in units of variable (not normalized). \\
\hline seasonal mean & Average for an individual year for a particular season. \\
\hline SIZE & Grid box size indicator. \\
\hline SN & Season or month indicator. \\
\hline sns & Seasons (DJF, MAM, JJA, SON). \\
\hline SON & September, October, November. \\
\hline SPAN & Span of years contributing to trend and IAV (includes first and last years contributing). \\
\hline TTME & Time of day for which group data apply. \\
\hline TRND & Trend. Slope of least-squares fit (change in average/yr). \\
\hline
\end{tabular}


Table 8 continued. Terms and Abbreviations Used

Term Meaning and description

TYPE Cloud or weather type code.

UNC Uncertainty of trend line; same units as TRND.

VAF Percent variance accounted for by the first harmonic.

YEAR

Year or years for which group data apply. Coded as 19yr for single years where yr gives the last 2 digits of the year, and as yfyl for multi-year averages where $y f=y r$ of the first year and $\mathrm{yl}=\mathrm{yr}$ of the last year of the period of record.

yrs Years. 


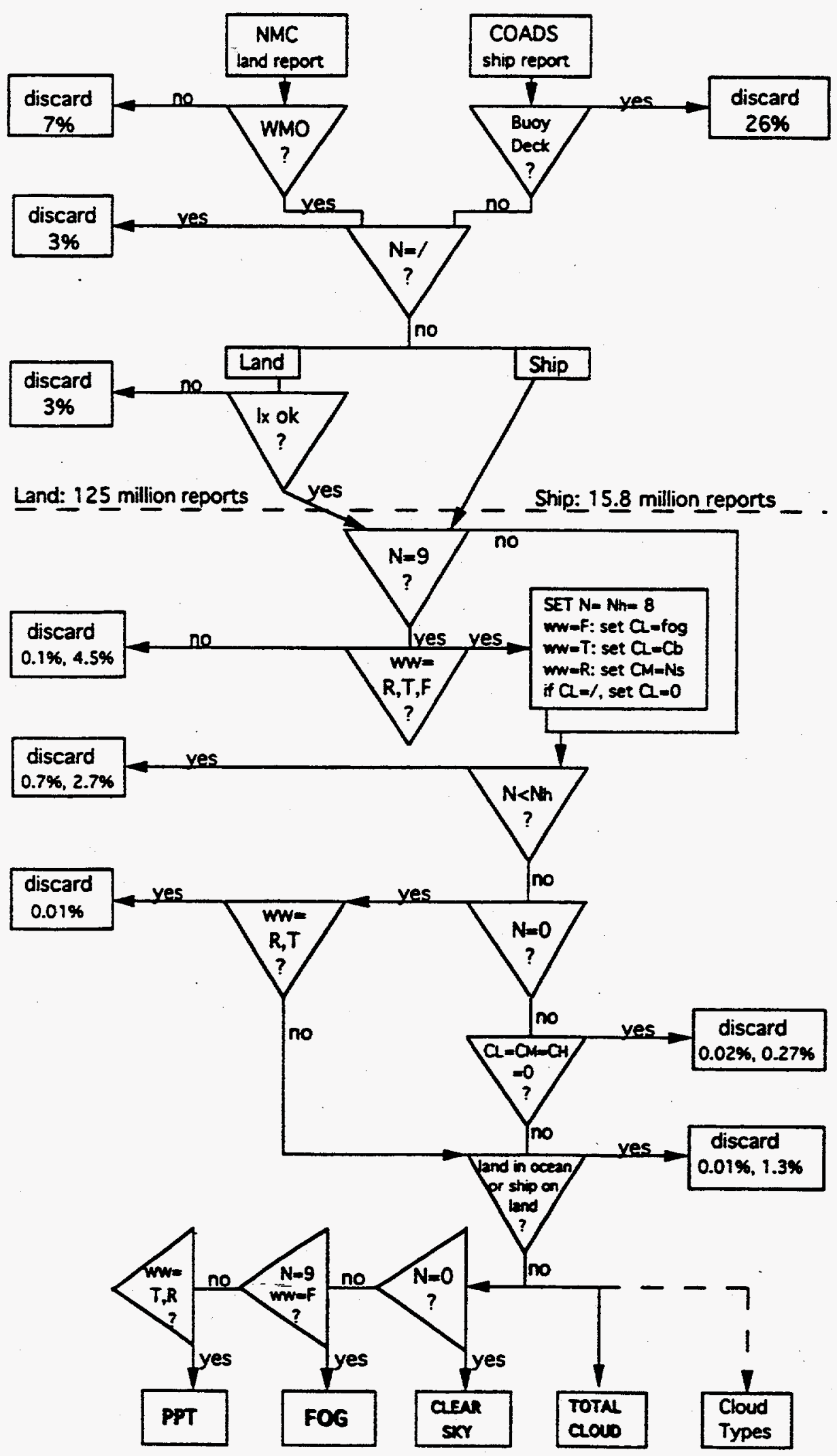

Figure 1. Flow chart of data selection and checking. Abbreviations are defined in Tables $1,2 \& 8$. (Discard fractions given in order "land, ship" where needed). See text for discussion. 


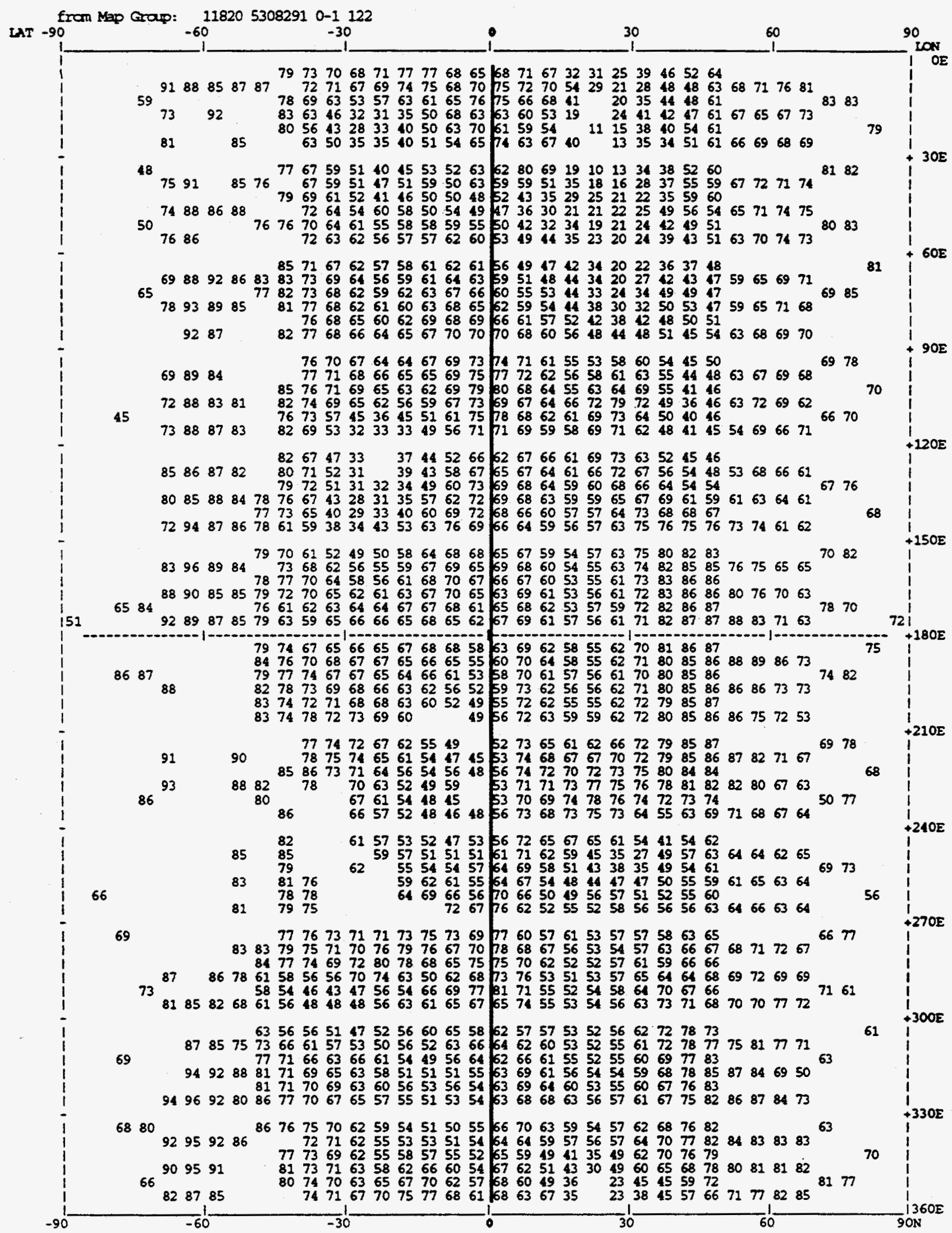

Figure 2a. ANNUAL AVERAGE TOTAL CLOUD COVER (\%), LAND \& OCEAN, 1982-1991 


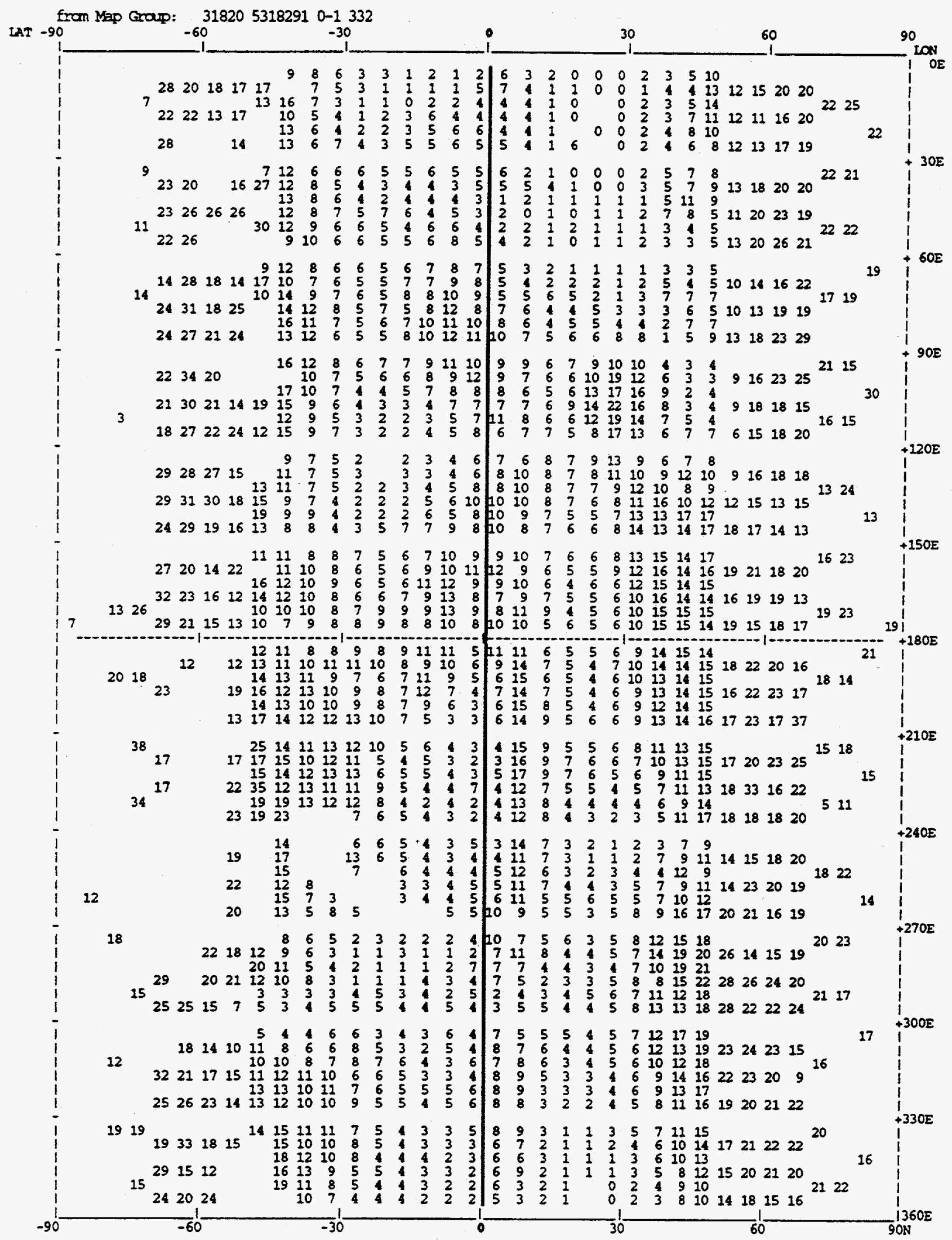

Figure 2b. ANNUAL PRECIPITATION FREQUENCY (\%), LAND \& OCEAN, 1982-1991 


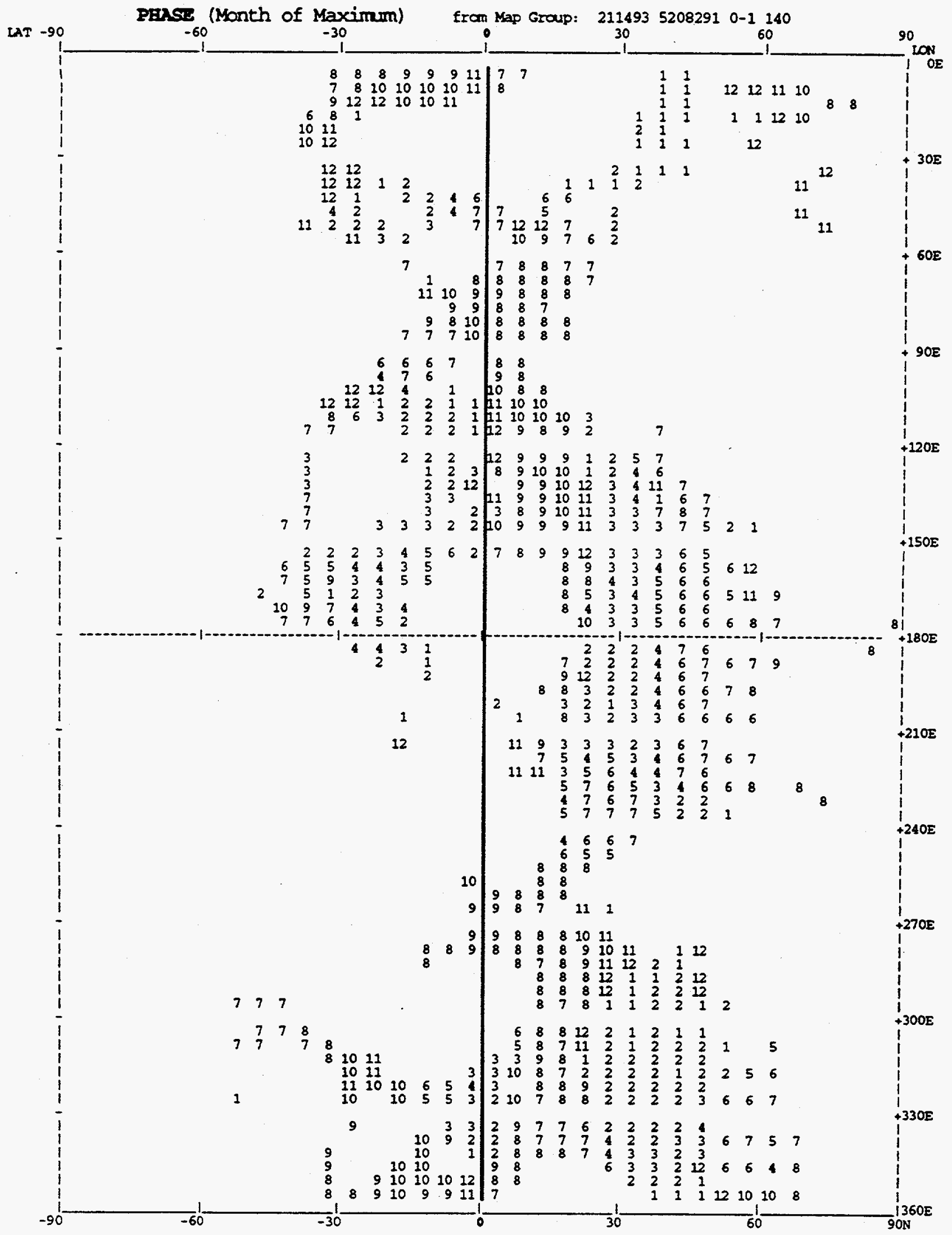

Figure 3a. ANNUAL CYCLE in Total Cloud Cover for (1982-1991) Ocean 


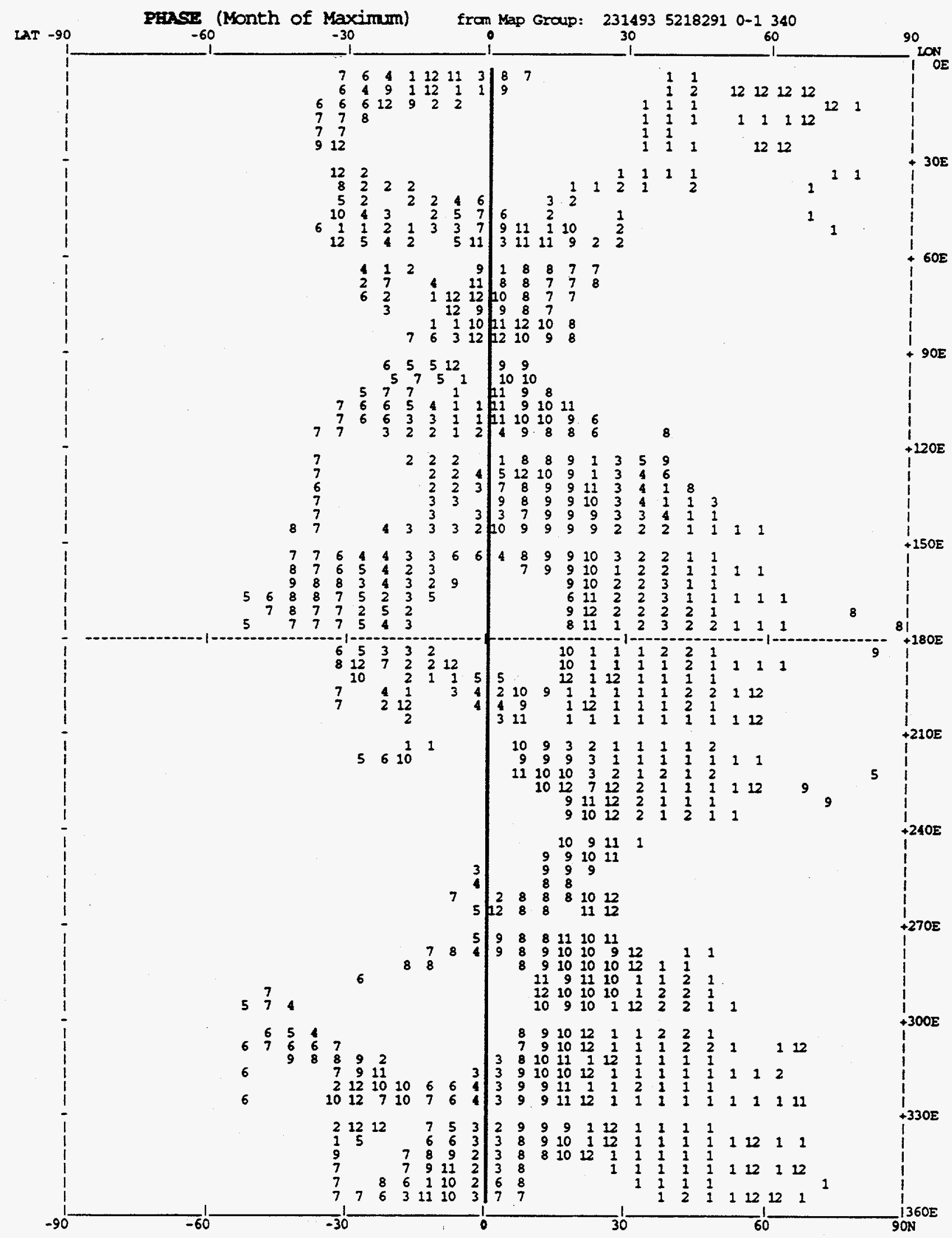

Figure 3b. ANNUAL CYCLE in Precipitation Frequency for (1982-1991) Ocean 


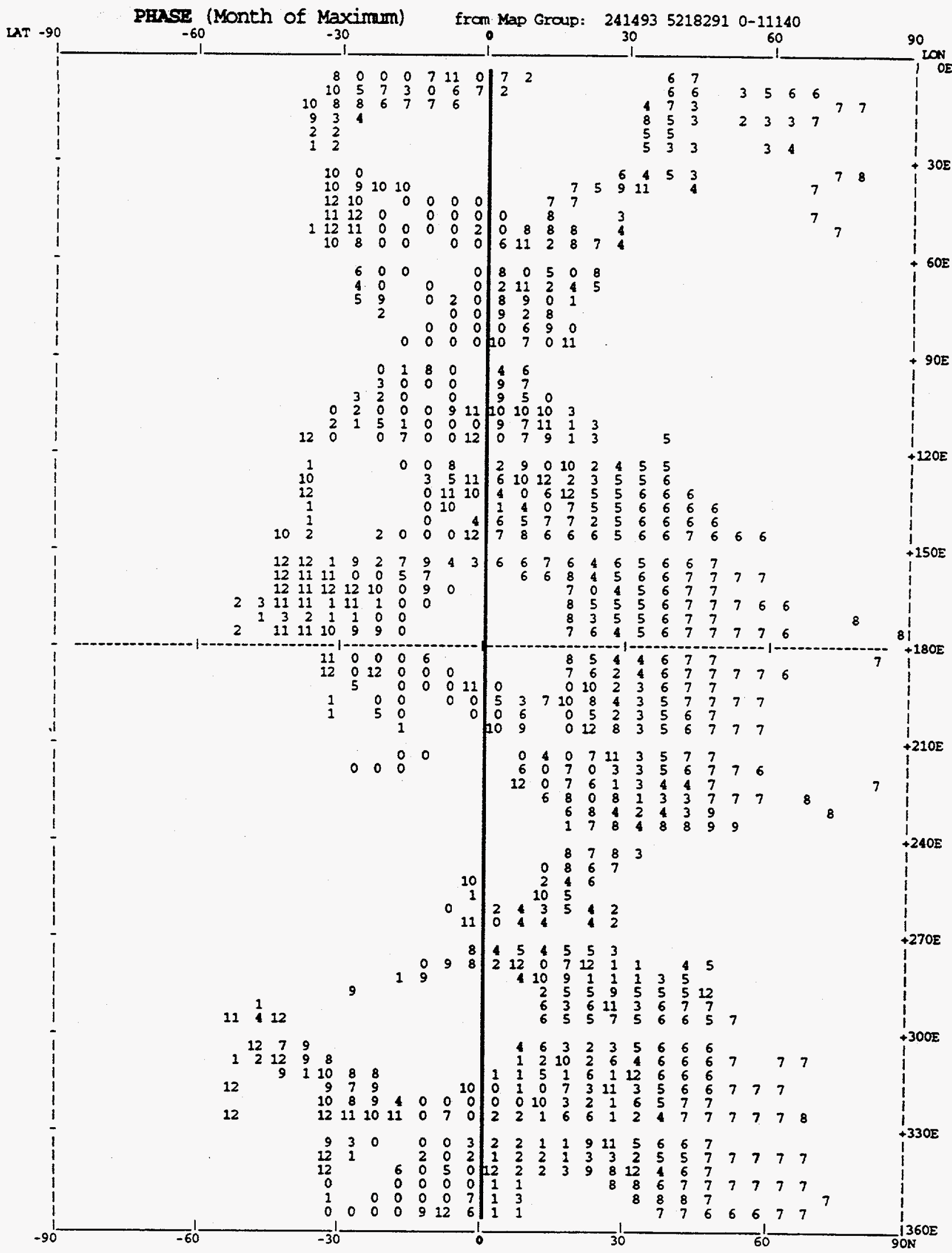

Figure 3c. ANNUAL CYCLE in Fog (sky obscured) Frequency for (1982-1991) Ocean 

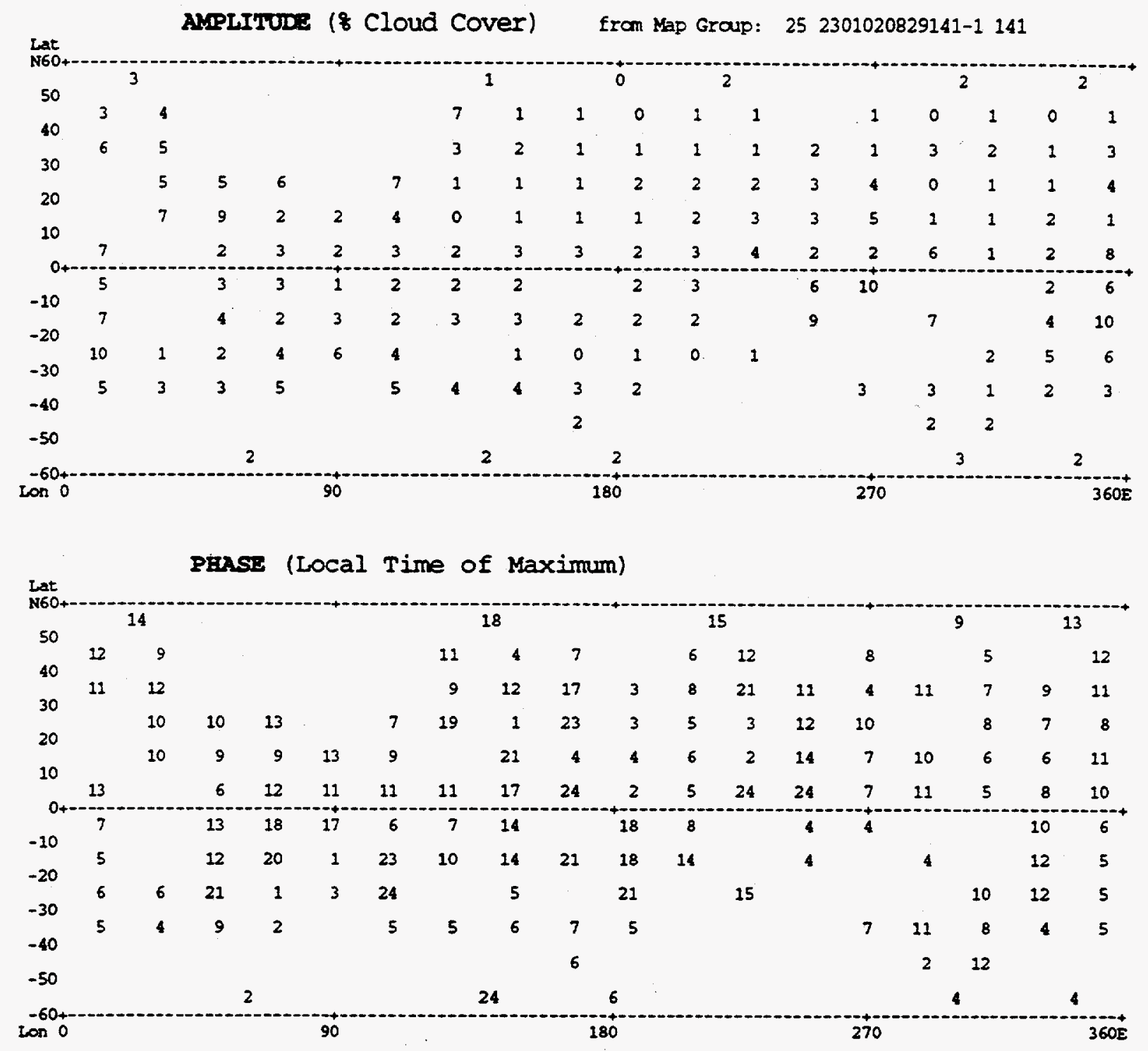

Figure 4a. DIURNAL CYCLE in Total Cloud Cover for DJF (1982-1991) Ocean 

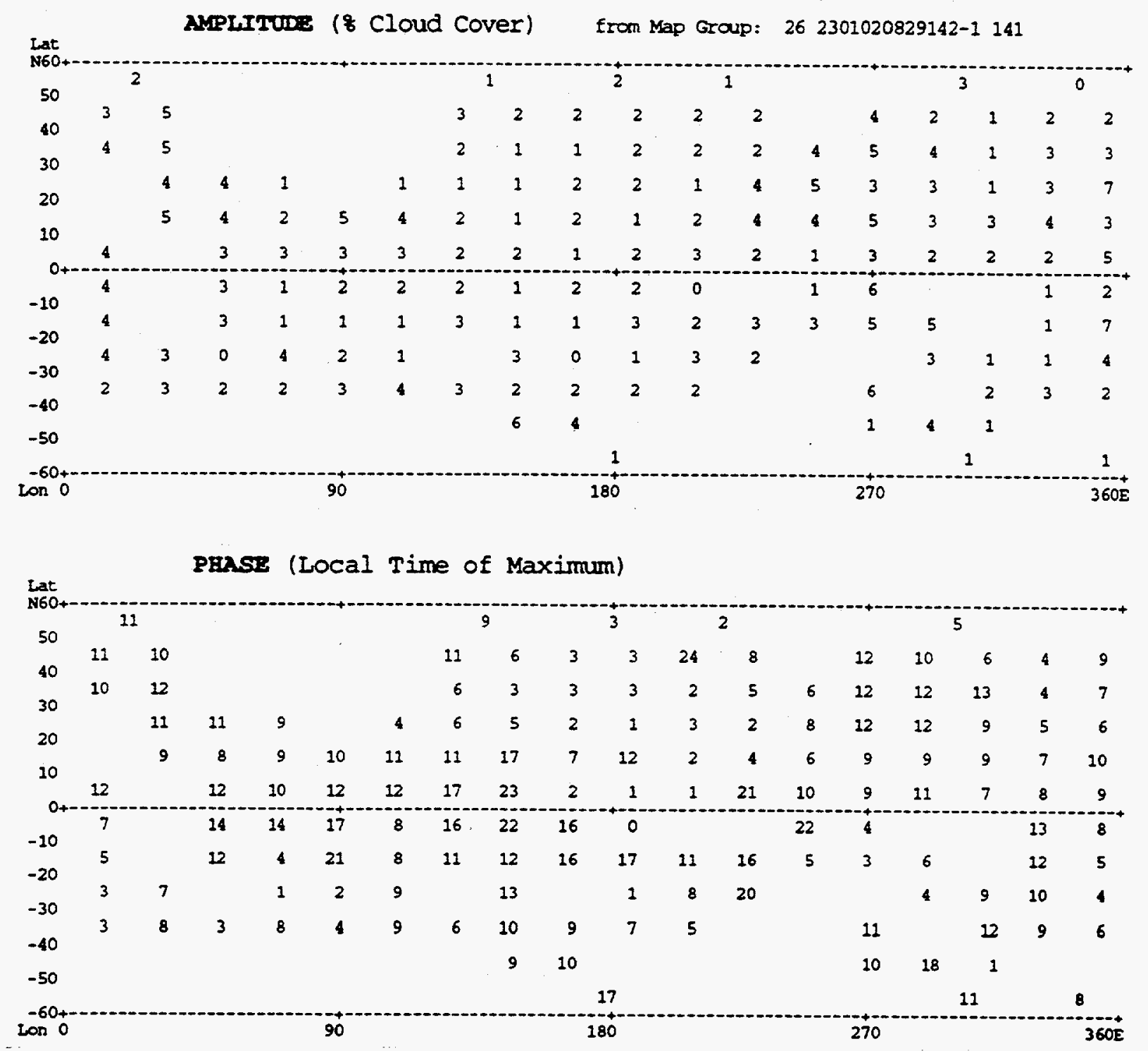

Figure 4b. DIURNAL CYCLE in Total Cloud Cover for MAM (1982-1991) Ocean 


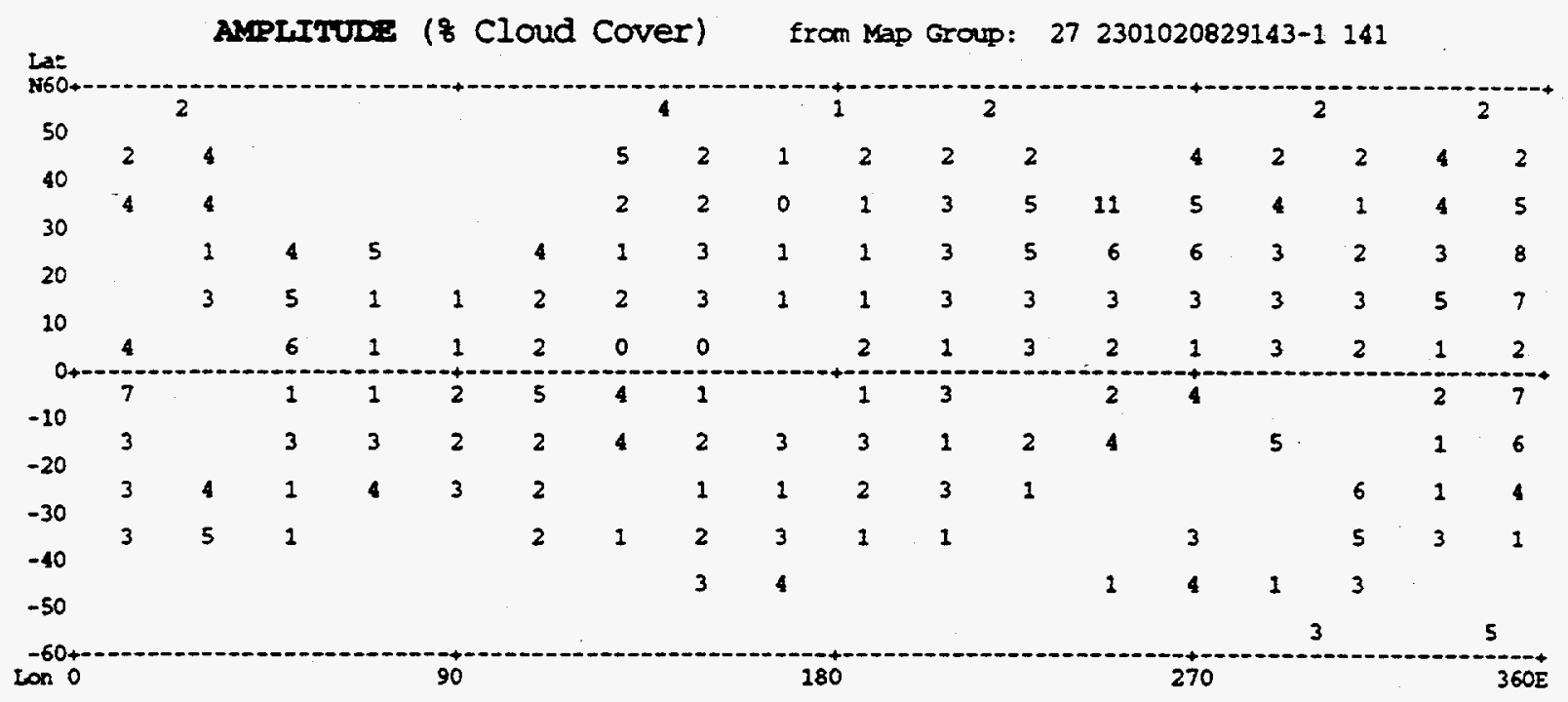

PRASE (Local Time of Maximum)

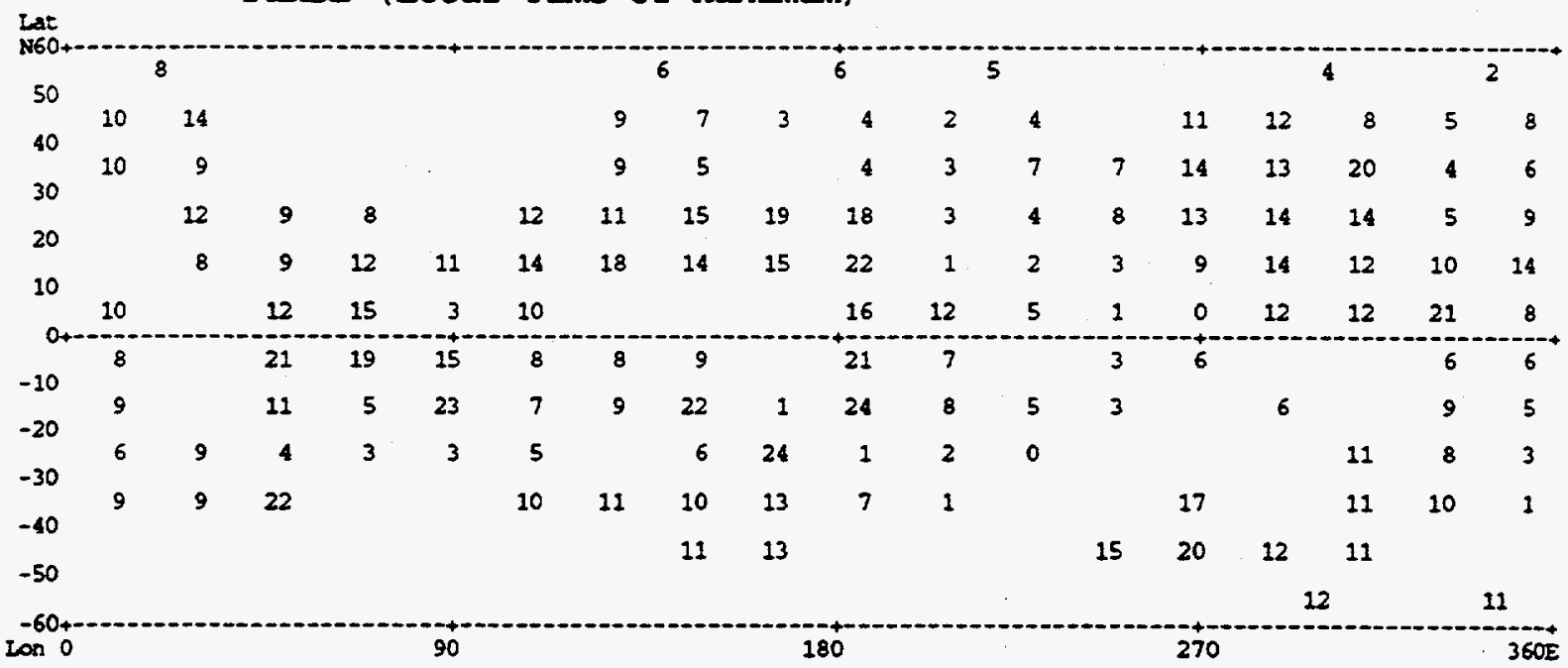

Figure 4c. DIURNAL CYCLE in Total Cloud Cover for JJA (1982-1991) Ocean 

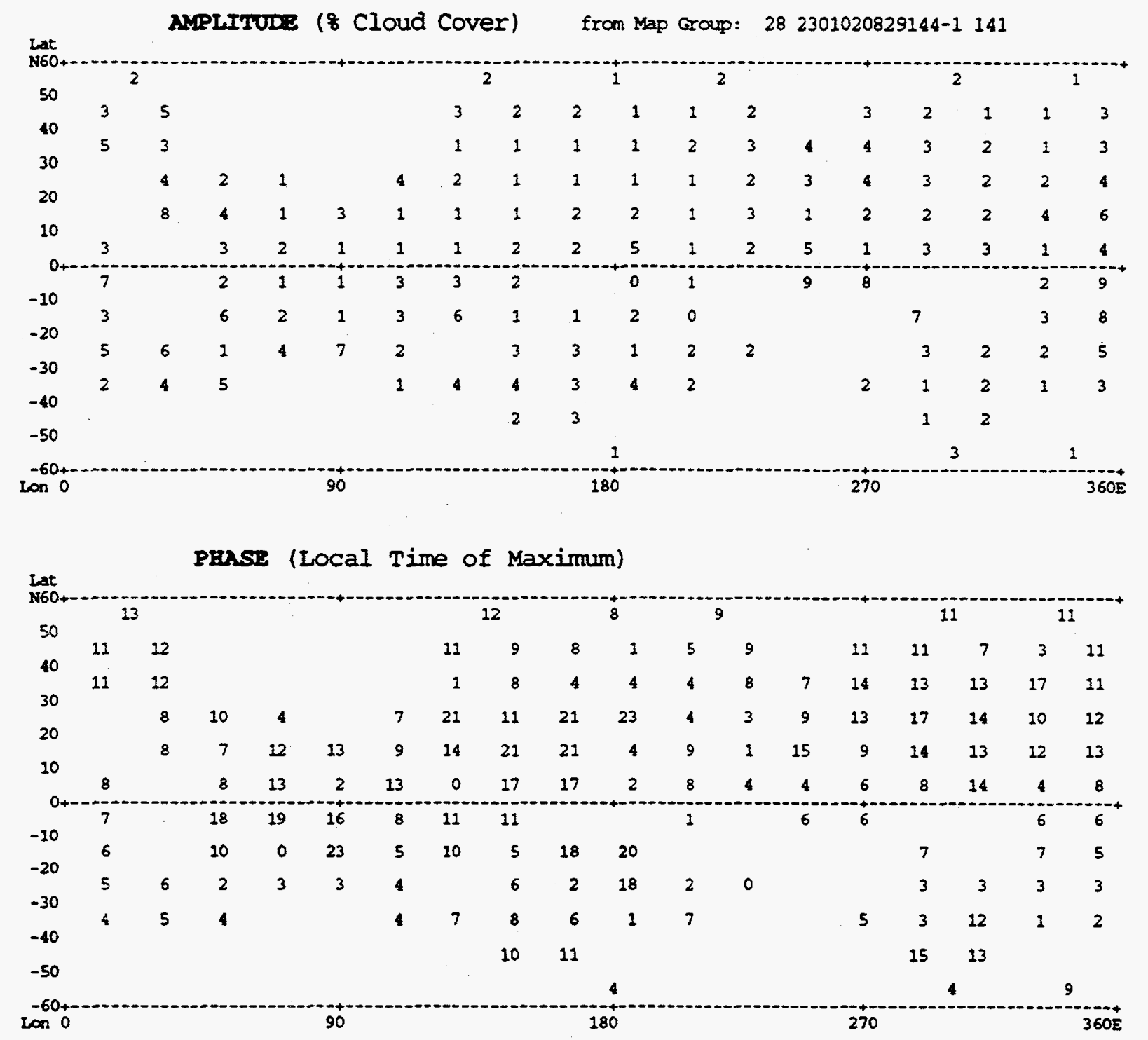

Figure 4d. DIURNAL CYCLE in Total Cloud Cover for SON (1982-1991) Ocean 


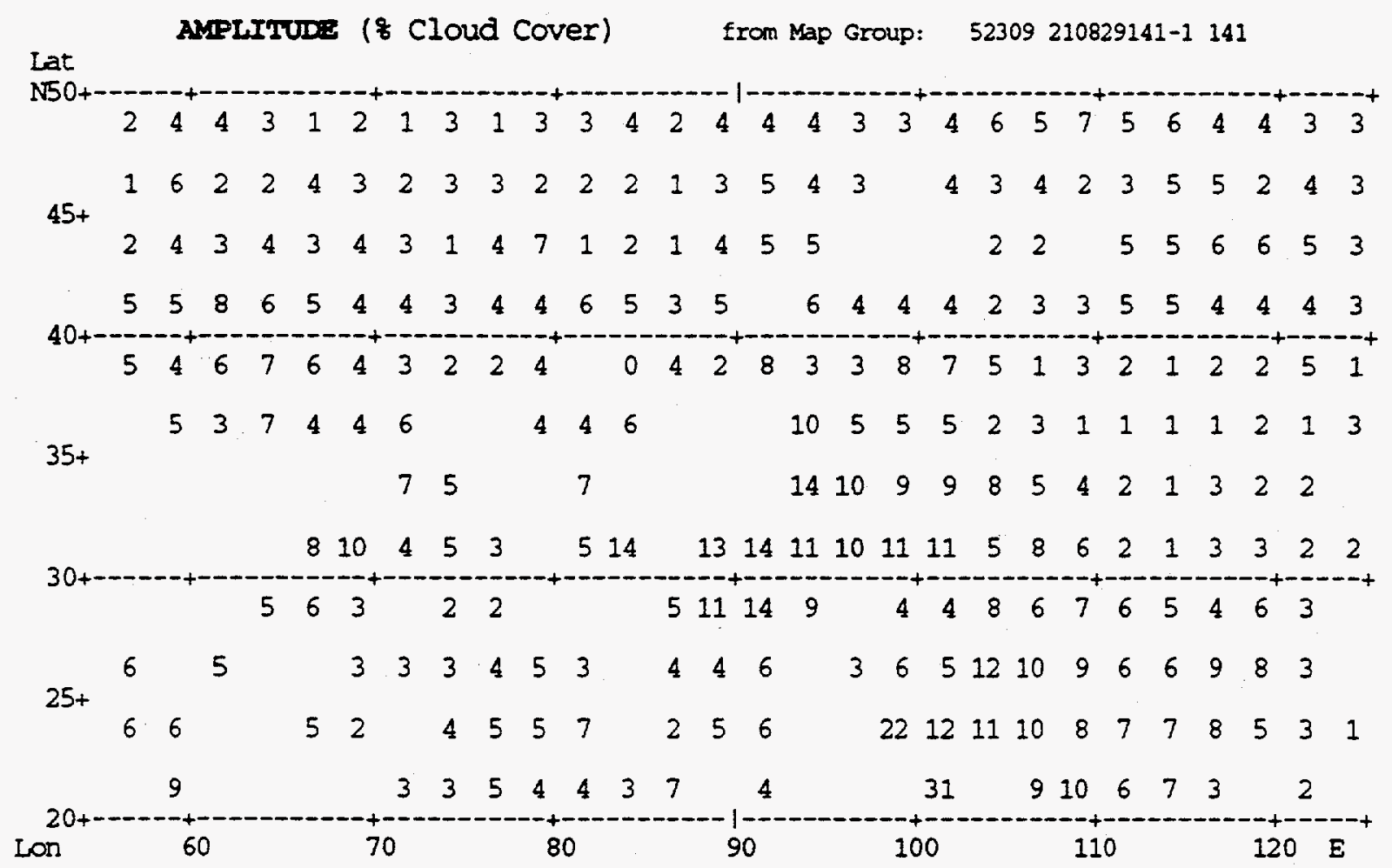

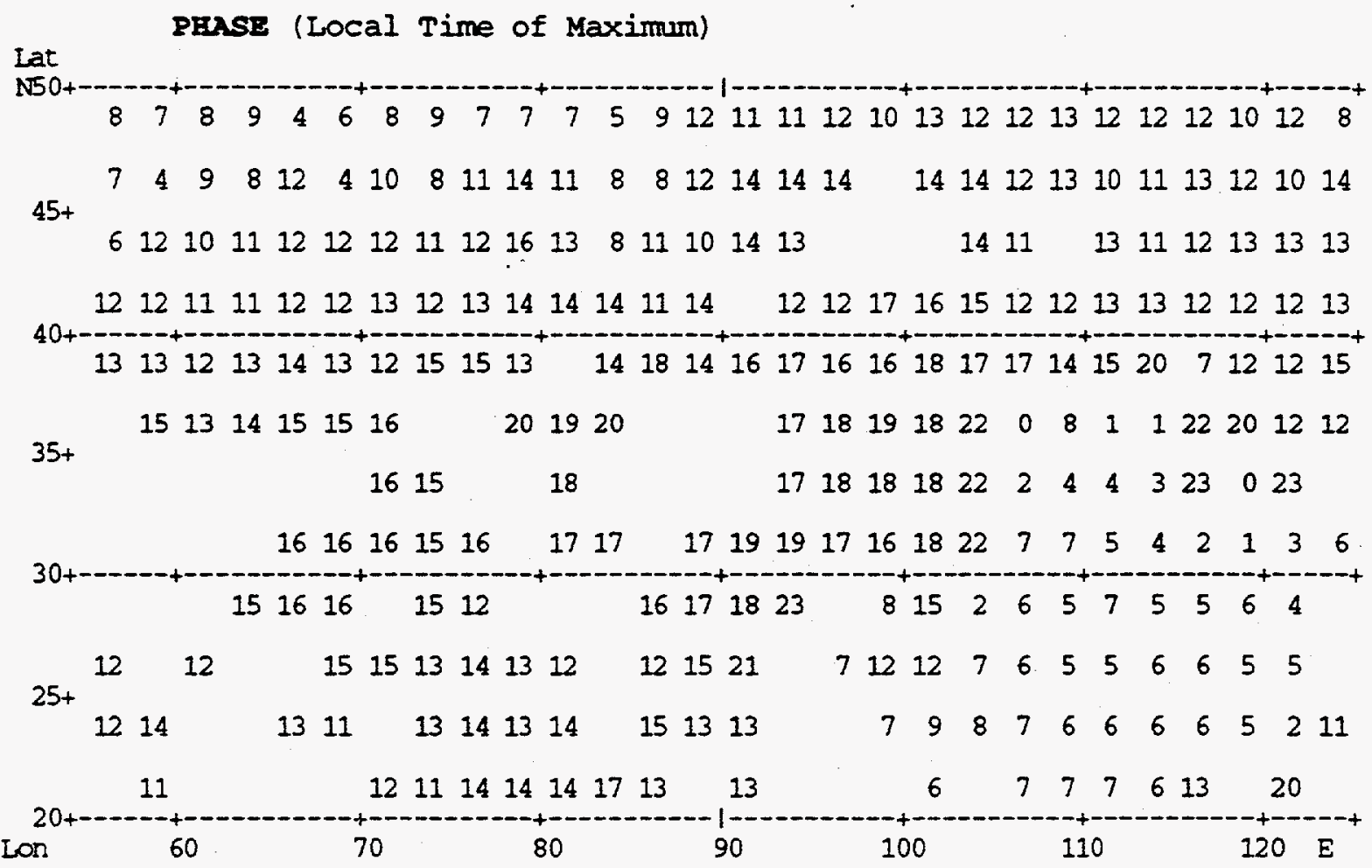

Figure 5a. DIURNAL CYCLE in Total Cloud Cover for DJF (1982-1991) Land over Asia 

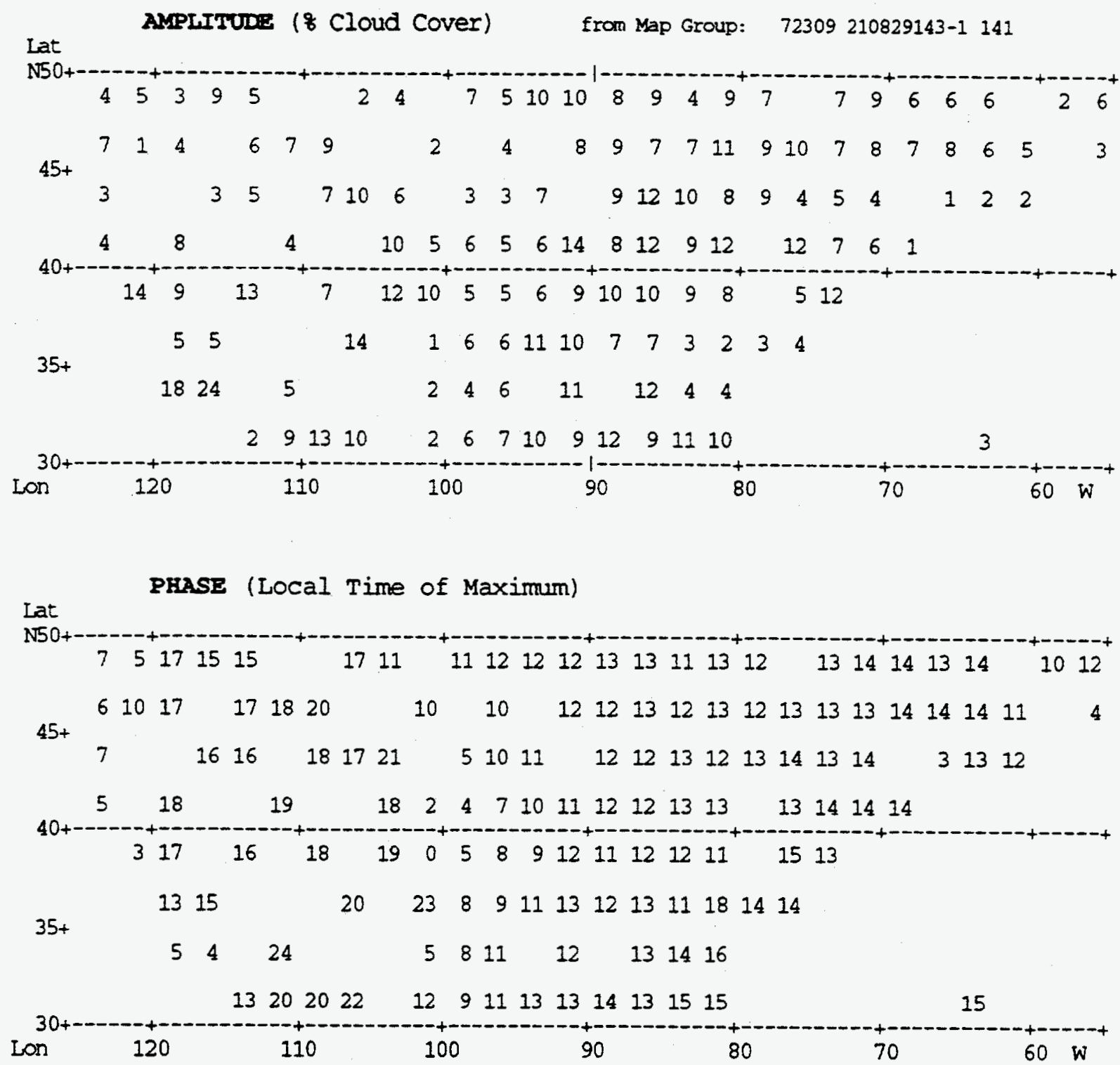

Figure 5b. DIURNAL CYCLE in Total Cloud Cover for JJA (1982-1991) Land over North America 


\section{INTERNAL DISTRIBUTION}

1. L. D. Bates

2. B. A. Berven

3. T. A. Boden

4. J. B. Cannon

5. J. H. Cushman

6. R. M. Cushman

7. V. H. Dale

8. M. P. Farrell

9. D. E. Fowler

10. R. L. Graham

11. S. G. Hildebrand

12. S. B. Jones

13. P. Kanciruk

14. J. M. Loar

15. L. J. Morris

16. D. E. Reichle

17. M. J. Sale

18. F. E. Sharples

19. D. E. Shepherd

20. P. Singley

21. S. H. Stow

22-221. CDIAC

222. Central Research Library

223-224. ESD Library

225-226. Laboratory Records Department

227. Laboratory Records, RC

228. ORNL Patent Section

229. ORNL Y-12 Technical Library

\section{EXTERNAL DISTRIBUTION}

230. S. S. Alexander, Pennsylvania State University, Department of Geosciences, 503 Deike Building, University Park, PA 16802

231. J. H. Allen, National Oceanic and Atmospheric Administration, National Geophysical Data Center Code E/GC2, 325 Broadway, Boulder, CO 80303

232. R. C. Barry, University of Colorado, World Data Center A, Glaciology, CIRES, Campus Box 449, Boulder, CO 80309-0449

233. M. A. Chinnery, National Oceanic and Atmospheric Administration, National Geophysical Data Center Code E/GC2, 325 Broadway, Boulder, CO 80303 
234. Roger C. Dahlman, Global Change Research Program, Environmental Sciences Division, Office of Health and Environmental Research, ER-74, U.S. Department of Energy, Washington, DC 20585

235. W. Draeger, EROS Data Center, U.S. Geological Survey, Sioux Falls, SD 57198

236. M. Dryer, National Oceanic and Atmospheric Administration, Space Environmental Lab., ERL/OAR, R/E/SE, 320 Broadway, Boulder, CO 80303

237. R. N. Farvolden, Professor, Department of Earth Sciences, University of Waterloo, Waterloo, Ontario N2L $3 \mathrm{Gl}$ Canada

238. J. Filson, National Earthquake Information Center, U.S. Geological Survey, Denver Federal Center, P.O. Box 20546, Denver, CO 80225

239. Jerry F. Franklin, Bloedel Professor of Ecosystem Analysis, College of Forest Resources, University of Washington, Anderson Hall (AR-10), Seattle, WA 98195

240. Dr. Diana W. Freckman, Director, College of Natural Resources, 101 Natural Resources Building, Colorado State University, Fort Collins, CO 80523

241. S. Graves, National Aeronautics and Space Administration Headquarters Code SED, 600 Independence Avenue, Washington, DC 20546

242. J. L. Green, National Space Science Data Center, NASA Goddard Space Flight Center, Code 630.2, Greenbelt, MD 20771

243. K. D. Hadeen, National Oceanic and Atmospheric Administration, NESDIS/NCDC, Federal Building MC E/CC, Asheville, NC 28801

244-248. Carole J. Hahn, Cooperative Institute for Research in Environmental Sciences, University of Colorado, Boulder, Colorado, 80309

249. R. C. Harriss, Institute for the Study of Earth, Oceans, and Space, Science and Engineering Research Building, University of New Hampshire, Durham, NH 03824

250. Ann Henderson-Sellers, MacQuarie University, North Rude, NSW, Sydney 2109, Australia

251. W. J. Hinze, Purdue University, Department of Earth and Atmospheric Sciences, West Lafayette, IN 47907

252. R. L. Jenne, NCAR, Scientific Computing Division, PO Box 3000, 1850 Table Mesa Drive, Boulder, Colorado 80307-3000

253. G. Y. Jordy, Director, Office of Program Analysis, Office of Energy Research, ER-30, G-226, U.S. Department of Energy, Washington, DC 20585 
254. Dennis Joseph, NCAR, Scientific Computing Division, PO Box 3000, 1850 Table Mesa Drive, Boulder, Colorado 80307-3000

255. Dr. Thomas R. Karl, National Climatic Data Center, Federal Building, 37 Battery Park Avenue, Asheville, NC 28801

256. D. Lauer, EROS Data Center, U.S. Geological Survey, Sioux Falls, SD 57198

257. S. Levitus, NOAA/National Oceanographic Data Center, 1825 Connecticut Avenue, NW, Washington, DC 20235

258-262. Julius London, Department of Astrophysical, Planetary and Atmospherice Sciences, University of Colorado, Boulder, Colorado 80309

263. M. S. Loughridge, National Oceanic and Atmospheric Administration, National Geophysical Data Center, Code E/GC3, 325 Broadway, Boulder, CO 80303

264. Peter Lunn, US Department of Energy, Environmental Sciences Division, Office of Energy Research, ER-74, Washington, DC 20585

265. H. M. McCammon, Acting Deputy Director, Environmental Sciences Division, Office of Health and Environmental Research, Office of Energy Research, ER-74, U.S. Department of Energy, Washington, DC 20585

266. R. H. Olsen, Vice President for Research, University of Michigan, Medical Science Building II, \#5605, 1301 East Catherine Street, Ann Arbor, MI 48109-0620

267. J. T. Overpeck, National Oceanic and Atmospheric Administration, National Geophysical Data Center, Paleoclimatology Program, 325 Broadway E/EC, Boulder, CO 80303

268. Farn Parnungo, ARL/NOAA/ERL, Boulder CO 80303

269. Bobbi Parra, US Department of Energy, Environmental Sciences Division, Office of Health and Environmental Research, Washington, DC 20585

270. Ari Patrinos, Acting Director Office of Health and Environmental Research, ER-74, U.S. Department of Energy, Washington, DC 20585

271. S. Ichtiaque Rasool, IGBP Data and Information System Office, Universite Paris, Tour 26,4 Etage, Aile 26-16, 4 Place Jussieu, 75230 Paris, Cedex 06, France

272. Michael R. Riches, Acting Director, Environmental Sciences Division, Office of Health and Environmental Research, ER-74, U.S. Department of Energy, Washington, DC 20585

273. S. Ruttenberg, Univ. Corporation for Atmospheric Research, CSNET, P. O. Box 3000, Boulder, CO 80307-3000 
274. G. S. Sayler, Professor, 10515 Research Drive, Suite 100, The University of Tennessee, Knoxville, TN 37932-2567

275. A. L. Shumbera, National Oceanic and Atmospheric Administration, WDC-A for Meteorology, National Climatic Data Center, Federal Building MC E/CC, Asheville, NC 28801

276. Mr. Peter M. Steurer, National Climatic Data Center, Federal Building, 37 Battery Park Avenue, Asheville, NC 28801

277. Jerry Stokes, Battelle Pacific Northwest Lab, Battelle, Blvd, MS K1-74, PO Box 999, Richland, Washington 99352

278-282. Stephen G. Warren, Department of Atmospheric Sciences, University of Washington, Seattle, Washington 98195

283. F. J. Wobber, Environmental Sciences Division, Office of Health and Environmental Research, Office of Energy Research, ER-74, U.S. Department of Energy, Washington, DC 20585

284. Office of Assistant Manager for Energy Research and Development, U.S. Department of Energy Oak Ridge Operations, P. O. Box 2001, Oak Ridge, TN 37831-8600

285-286. Office of Scientific and Technical Information, P. O. Box 62, Oak Ridge, TN 37831 